\title{
Echocardiographic guidance in transcatheter structural cardiac interventions
}

\author{
Eustachio Agricola ${ }^{1 *}$, MD; Francesco Meucci², MD; Francesco Ancona $^{1}, \mathrm{MD}$; Ana Pardo Sanz ${ }^{3}, \mathrm{MD}, \mathrm{PhD}$; \\ José Luis Zamorano ${ }^{3}, \mathrm{MD}, \mathrm{PhD}$ \\ 1. Cardiovascular Imaging Unit, Cardio-Thoracic-Vascular Department, IRCCS San Raffaele Scientific Institute, Milan, Italy; \\ 2. Structural Interventional Cardiology, Careggi University Hospital, Florence, Italy; 3. Centro de Investigación Biomédica en \\ Red en Enfermedades Cardiovasculares (CIBERCV), University Hospital Ramón y Cajal, Madrid, Spain
}

This paper also includes supplementary data published online at: https://eurointervention.pcronline.com/doi/10.4244/EIJ-D-21-00582

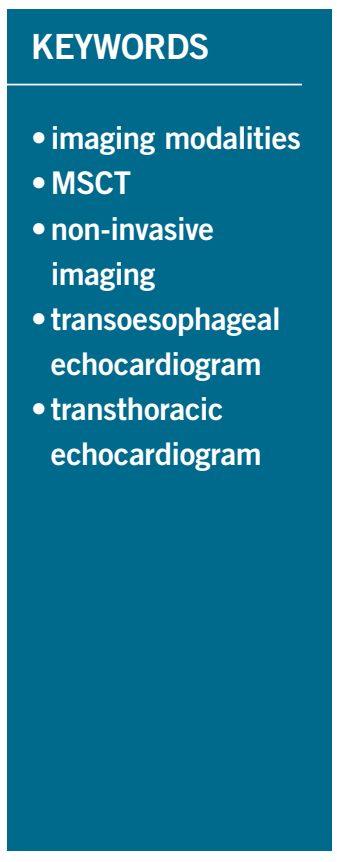

\begin{abstract}
Catheter-based treatment of structural heart diseases (SHD) has seen tremendous advances in the past decades, thanks to the development of new devices and advances in imaging techniques. Today, we have an extensive armamentarium of imaging tools for preprocedural planning, intraprocedural guidance and follow-up of SHD. Intraprocedural guidance is based mainly on transoesophageal echocardiography; however, other imaging modalities are used as complementary or alternative techniques, each of them with its strengths and weaknesses. Thus, a multimodality imaging approach provides added values in this setting. As the field of imaging parallels the continuous technical improvements, this review will describe the state of the art imaging techniques, focusing on echocardiography during procedural guidance of the most common catheter-based interventions, providing tips and tricks for interventional cardiologists: in particular, how to guide transseptal crossing; left atrial appendage closure; transcatheter mitral or tricuspid valve repair or replacement; percutaneous closure of patent foramen ovale and atrial defects; and percutaneous closure of paravalvular leaks. Open challenges for the near future are the need for physicians with specific technical skills and competencies in SHD imaging, more attention to high levels of radiation exposure, and optimisation of intraprocedural and post-procedural evaluation.
\end{abstract}

*Corresponding author: Cardio-Thoracic-Vascular Department, San Raffaele Scientific Institute, Via Olgettina 60, 20132 Milan, Italy.E-mail: agricola.eustachio@hsr.it 


\section{Abbreviations}

3D

3DE 3D echocardiography

AP anteroposterior

ASD atrial septal defect

CAU caudal

CRA cranial

CS coronary sinus

CT computed tomography

FO fossa ovalis

IAS interatrial septum

ICE intracardiac echocardiography

LA left atrium

LAA left atrial appendage

LAO left anterior oblique

LAX long axis

LV left ventricle

LVOT left ventricular outflow

MPR multiplanar reconstruction

MR mitral regurgitation

MV mitral valve

PISA proximal isovelocity surface area

PVL paravalvular leak right anterior oblique

RCA

RV

SAX

SHD

TCD

TMVI

TOE

TR

TSP

TTE

TV

VSD

\section{Introduction}

The past two decades have seen tremendous advances in the catheter-based treatment of structural heart diseases (SHD) thanks to the development of new devices with improved performance and advances in imaging techniques.

Cardiac imaging in the catheter-based treatment of SHD has come a long way in the past 70 years (Figure 1). Indeed, since the pioneering work by Rubio-Alvares and Limon in 1952 to relieve critical pulmonic valve stenosis, when a simple chest

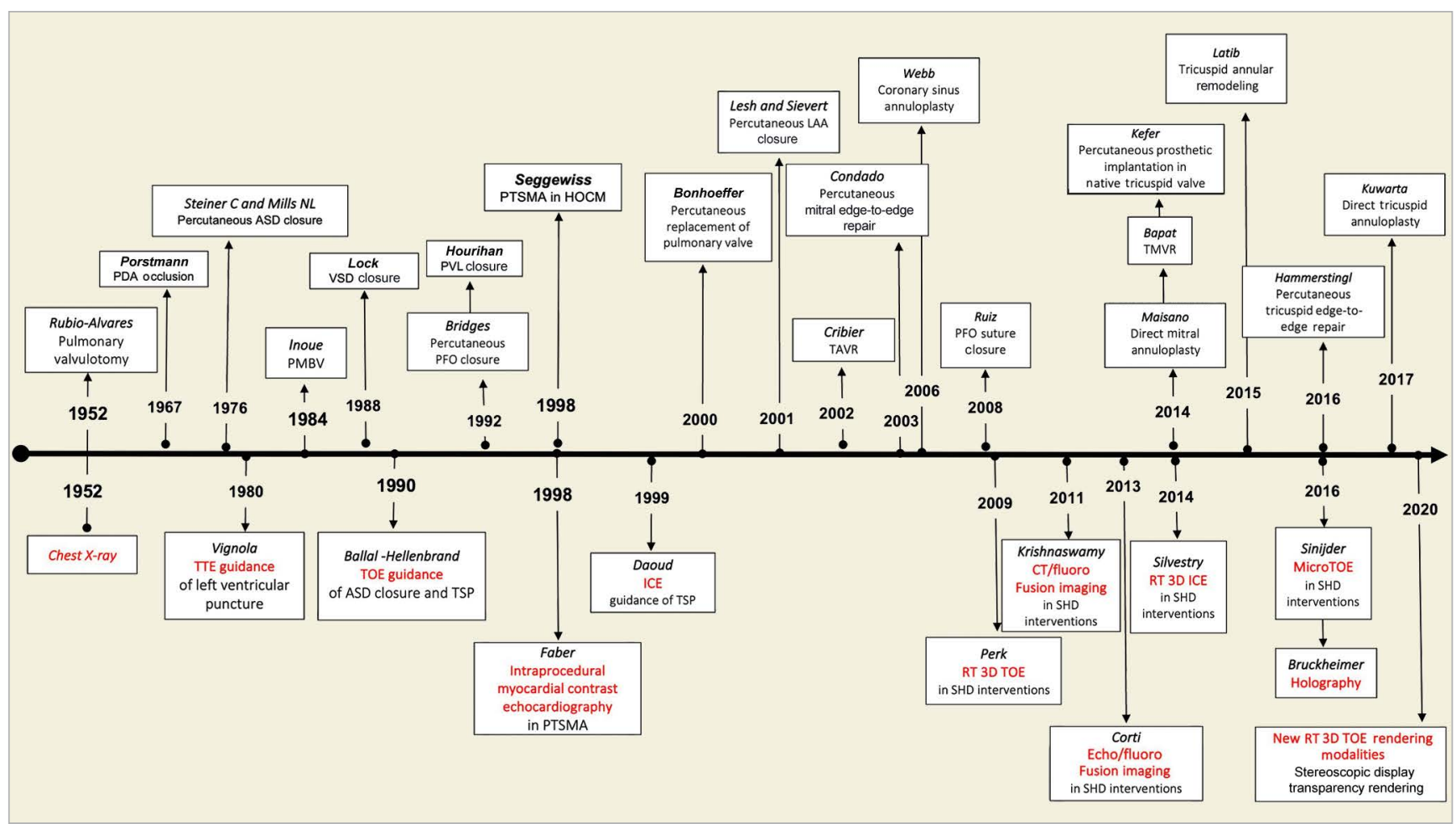

Figure 1. History and evolution of SHD intervention and interventional imaging. ASD: atrial septal defect; CT: computed tomography; HOCM: hypertrophic obstructive cardiomyopathy; ICE: intracardiac echocardiography; LAA: left atrial appendage; PDA: patent ductus arteriosus; PFO: patent foramen ovalis; PMBV: percutaneous mitral balloon valvuloplasty; PTSMA: percutaneous transluminal septal myocardial ablation; PVL: paravalvular leak; RT: real time; SHD: structural heart disease; TAVR: transcatheter aortic valve replacement; TMVR: transcatheter mitral valve replacement; TOE: transoesophageal echocardiography; TSP: transseptal puncture; TTE: transthoracic echocardiography; VSD: ventricular septal defect 
X-ray was the only modality allowing visualisation of the heart, a cascade of procedural and technological advances has followed ${ }^{1}$. Transthoracic echocardiography (TTE) first appeared in the cath lab in the $1980 \mathrm{~s}^{2}$. Two-dimensional (2D) transoesophageal echocardiography (TOE) started to be developed in the late 1970s and made its first appearance as intraprocedural imaging guidance in $1990^{3,4}$. Throughout the past three decades, TOE technology has progressed from single-plane to three-dimensional (3D) transducers. It has become the leading preprocedural and intraprocedural cardiac imaging modality in SHD interventions. At the same time, other alternative/complementary imaging tools to conventional TOE have been developed and introduced, such as the micro TOE probe and intracardiac echocardiography (ICE) $)^{5,6}$. The micro TOE probe (S8-3t microTOE probe [Philips Healthcare]; ClariTEE [ImaCor]) can be introduced transorally or transnasally using local anaesthesia only, and offers sufficient image quality compared to conventional TOE and ICE. Promising results have been reported to guide transseptal puncture (TSP) and left atrial appendage (LAA) closure ${ }^{6}$. ICE may have some advantages over TOE: it is more comfortable for the patient, avoids the use of general anaesthesia and potentially allows a single-operator procedure. In recent years, advances in technology have allowed the development and successful implementation of real-time 3D ultrasound in ICE, which is crucial for applications in SHD procedures such as TSP, LAA closure, transcatheter tricuspid interventions, etc.

Today, we undoubtedly have an armamentarium of imaging tools providing excellent imaging quality. However, each of them has its strengths and weaknesses. Therefore, multimodality imaging utilising several imaging techniques together may provide added value in terms of procedural planning and efficacy by combining the individual strength of each imaging modality. Recently, fusion imaging as a combined "hybrid" procedure of several imaging modalities has gained attention ${ }^{7,8}$. Its major advantages include the optimised multidimensional view with an excellent spatial resolution, anatomic orientation, visualisation of soft tissue onto fluoroscopic view, allowing better procedural navigation with fluoroscopy and with less use of contrast medium.

The last frontier of interventional imaging is to overcome the way $3 \mathrm{D}$ images are displayed and to increase the ability of interacting with them. The images acquired are usually presented on 2D displays, thereby limiting their usefulness and the ability to interact with them. Holographic images, created in real time from the volumetric data, which float in the air during the procedure in front of the operator and above the patient, could provide an intuitive and interactive display for the interventionalist, and may improve procedure outcomes ${ }^{9}$.

This review will describe the use of imaging techniques, focusing attention on echocardiography during procedural guidance of the most common catheter-based interventions of SHD, providing some tips and tricks for the practical interventional cardiologist (Central illustration).

\section{TRANSSEPTAL PUNCTURE}

The transseptal crossing is the common front door for many leftside catheter-based procedures. Experienced operators may safely perform a TSP using only fluoroscopy. On the other hand, imaging

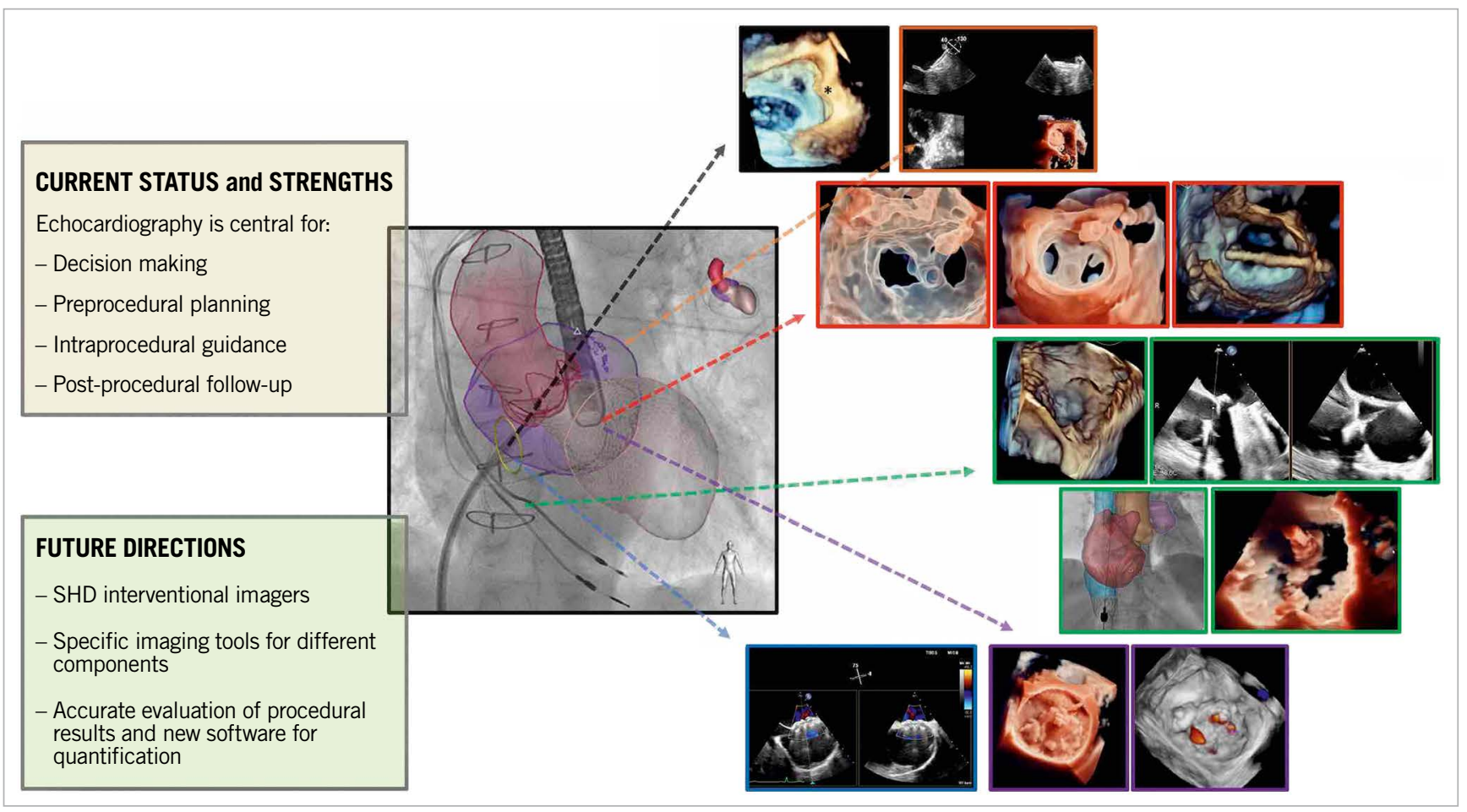

Central illustration. Echocardiographic guidance for transcatheter structural cardiac interventions. 
guidance mainly performed by TOE is mandatory for a targeted/ site-specific TSP for the majority of structural interventions, and it is also helpful during the initial phase of training.

\section{PROCEDURAL STEPS AND IMAGING GUIDANCE}

The interatrial septum (IAS) may be displayed by fluoroscopy and TOE in different anatomical projections and perspectives to define the optimal target for TSP (Figure 2) ${ }^{10}$.

The procedural steps are described in Figure $\mathbf{3}$ and Supplementary Table 1.

TOE is of the utmost importance to identify complications promptly, e.g., cardiac perforation (right and/or left atrium or the aorta), thrombus formation, or ST-segment elevation (due to air embolism in the right coronary).

Fusion imaging can provide added value during TSP as follows (Figure 4A-Figure 4D $)^{11}$. 1) No predefined fluoroscopic angulation is anatomically consistent in all patients. Thus, fusion imaging may be useful for achieving a patient-tailored fluoroscopic view. 2) The catheter and the fossa ovalis (FO) are simultaneously visualised on the fluoroscopic screen, allowing operators to understand the spatial position of the catheter according to superior-inferior and anterior-posterior directions. 3) The downwards pull of the catheter towards the IAS can be monitored by the $2 \mathrm{D}$ bicaval view superimposed on the left anterior oblique (LAO) projection, in which the side-on profile of the IAS is well visualised and the tenting can be clearly appreciated. Alternatively, the tenting can be looked for by cropping a $3 \mathrm{D}$ volume dataset until the tenting becomes visible in the lateral perspective.

In addition, there are options to superimpose onto the fluoroscopic view the anatomical models of relevant structures based on a co-registered TOE sequence (Figure 4E, Figure 4F).

\section{LEFT ATRIAL APPENDAGE CLOSURE}

LAA closure aims to prevent stroke in patients with non-valvular atrial fibrillation by excluding the LAA from systemic circulation. Echocardiographic imaging is of paramount importance for correct procedural planning, safety and procedural success.

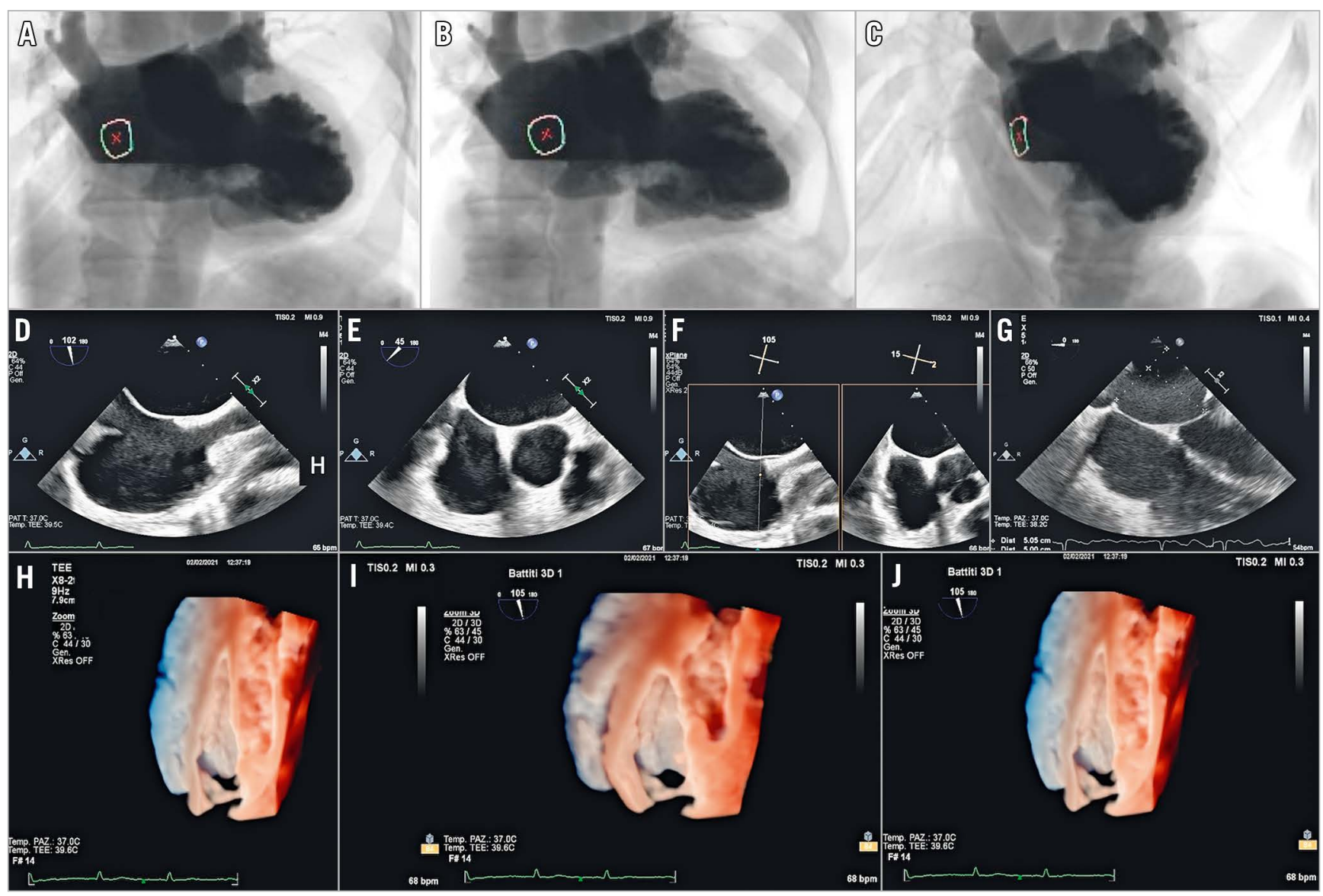

Figure 2. Recommended imaging modalities to display IAS. A) Anteroposterior projection: the IAS is displayed in an oblique perspective corresponding to the $3 D$ oblique perspective from right atrium $(H)$. B) Right anterior oblique projection: the IAS is displayed in en face perspective, corresponding to the $3 D$ en face view from the right atrium (I). C) Left anterior oblique projection: the side-on profile of the IAS corresponding to either the $3 D$ lateral perspective $(J)$ or $2 D$ bicaval view $\left(90-120^{\circ}\right)(D)$. D) Superior-inferior orientation. E) Short-axis $(S A X)$ view at the base (30-50 ) for anterior-posterior orientation. F) Biplane view that displays both the bicaval and the SAX view simultaneously. $G)$ Four-chamber view $\left(0^{\circ}\right)$ to determine the height above the mitral valve. 

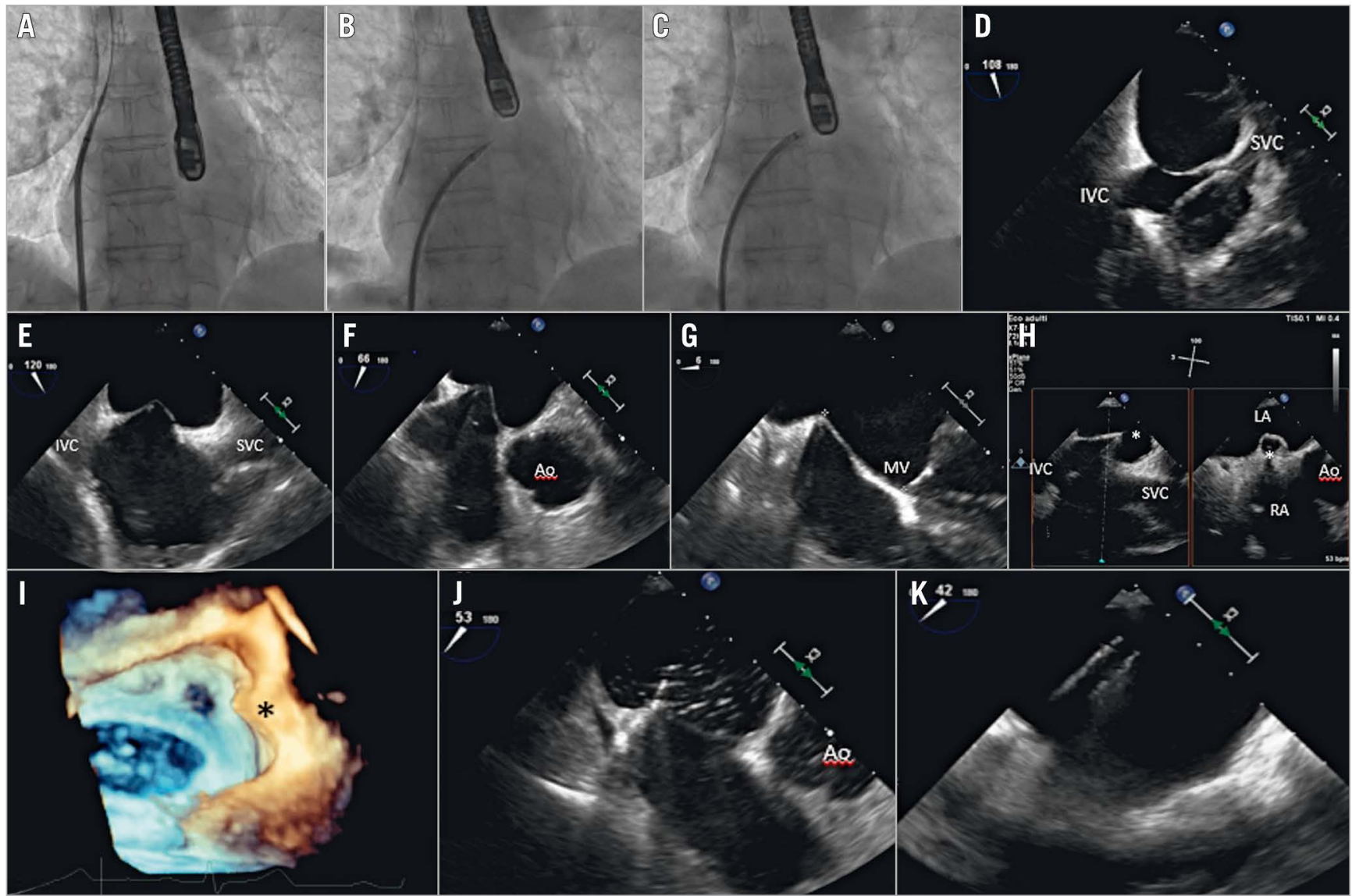

Figure 3. Procedural steps of TSP. A-C) Anteroposterior fluoroscopic projection showing the progressive steps of the TSP. A) Guidewire in the $S V C . B)$ The catheter and needle in the FO and then the septum is punctured. C) The septum is crossed and the needle is removed. D) $2 D$ TOE mid-oesophageal bicaval view showing the catheter tip coursing from the SVC to the FO. E-H) Sequential 2D TOE views showing the

"tenting" of the catheter against the FO. I) 3DE overhead view showing the septum and the tenting (asterisk) in lateral perspective. J) Septal crossing confirmed by the transient appearance of bubbles in the LA. K) Catheter in the LA. 3DE: three-dimensional echocardiography; Ao: aorta; FO: fossa ovalis; IVC: inferior vena cava; LA: left atrium; MV: mitral valve; RA: right atrium; SVC: superior vena cava; TOE: transoesophageal echocardiography

\section{PROCEDURAL PLANNING}

2D and 3D TOE has traditionally been the cornerstone of preprocedural evaluation and procedural planning for LAA closure. It allows an accurate description of the morphological features of the LA and the LAA, measurement of the dimensions of the ostium and the length of LAA, assessment of the number and configuration of its lobes and the presence of intraluminal thrombi, as well as providing relevant information on the surrounding structures ${ }^{12}$ (Figure 5).

Computed tomography (CT) has been increasingly used for preprocedural evaluation of LAA closure due to its high spatial resolution. Thanks to $3 \mathrm{D}$ volume rendering and multiplanar reconstruction (MPR), the interventionalist is not only able to reconstruct the threedimensional anatomy of the pertinent structures and obtain precise LAA ostial dimensions, but can also calculate the most convenient fluoroscopic projections to use during the procedure, and potentially spare $\mathrm{X}$-ray exposure and contrast medium usage. Moreover, CT is highly sensitive in excluding the presence of intraluminal filling defects ${ }^{13}$.

In order to select the proper device, the LAA dimensions and morphology need to be thoroughly assessed during the preprocedural planning, and confirmed intraprocedurally after ensuring adequate volume repletion of the patient to avoid undersizing of the device ${ }^{14}$. Device sizing is calculated using different segments according to the type of the device (Figure 6). However, the dimensions of the LAA ostium (the most proximal portion of the LAA, defined by an imaginary line connecting the axial image of left circumflex artery and the most proximal portion of the Marshall band), the neck (the tubular portion of the LAA approximately $1 \mathrm{~cm}$ distal to the ostium) and the depth of the LAA are the parameters necessary for appropriate device sizing. Any proximally originating lobes or accessory lobes and trabeculations should be reported as they may interfere with the device positioning guidance and mislead the interventionalist to attempt to release the device more distally or proximally than usual.

\section{PROCEDURAL STEPS AND IMAGING GUIDANCE}

The procedure is usually guided by fluoroscopy and TOE; ICE can be used instead of TOE in selected cases. 


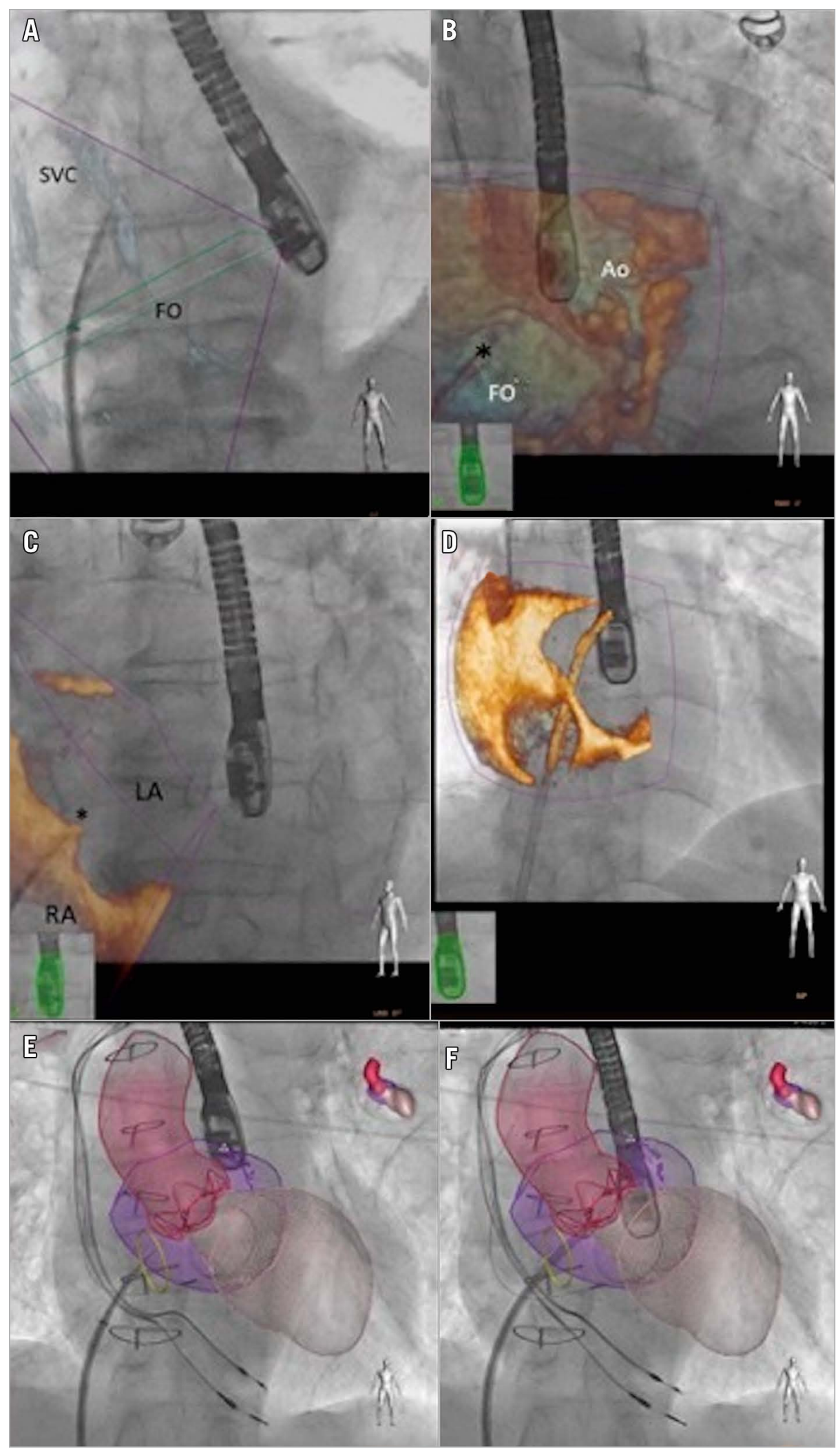

Figure 4. Fusion imaging guidance of TSP. A) Patient-tailored anteroposterior (AP) fluoroscopic view "fused" with a $2 D$ bicaval view of the $I A S$, showing the dilator coursing from the SVC to the FO. B) AP fluoroscopic view "fused" with a $3 D$ en face view of the IAS from the RA, showing the fine position of the catheter tip into the FO.C) $3 D$ lateral perspective of the IAS superimposed on an APfluoroscopic projection showing the tenting (*). D) 3D oblique perspective of the IAS superimposed on an AP fluoroscopic view showing septal crossing. E) \& F) Heart models obtained from 3D data sets and superimposed on the fluoroscopic view. The FO is identified by a yellow circle. Ao: aorta; AP: anterioposterior; FO: fossa ovalis; LA: left atrium; RA: right atrium; SVC: superior vena cava 


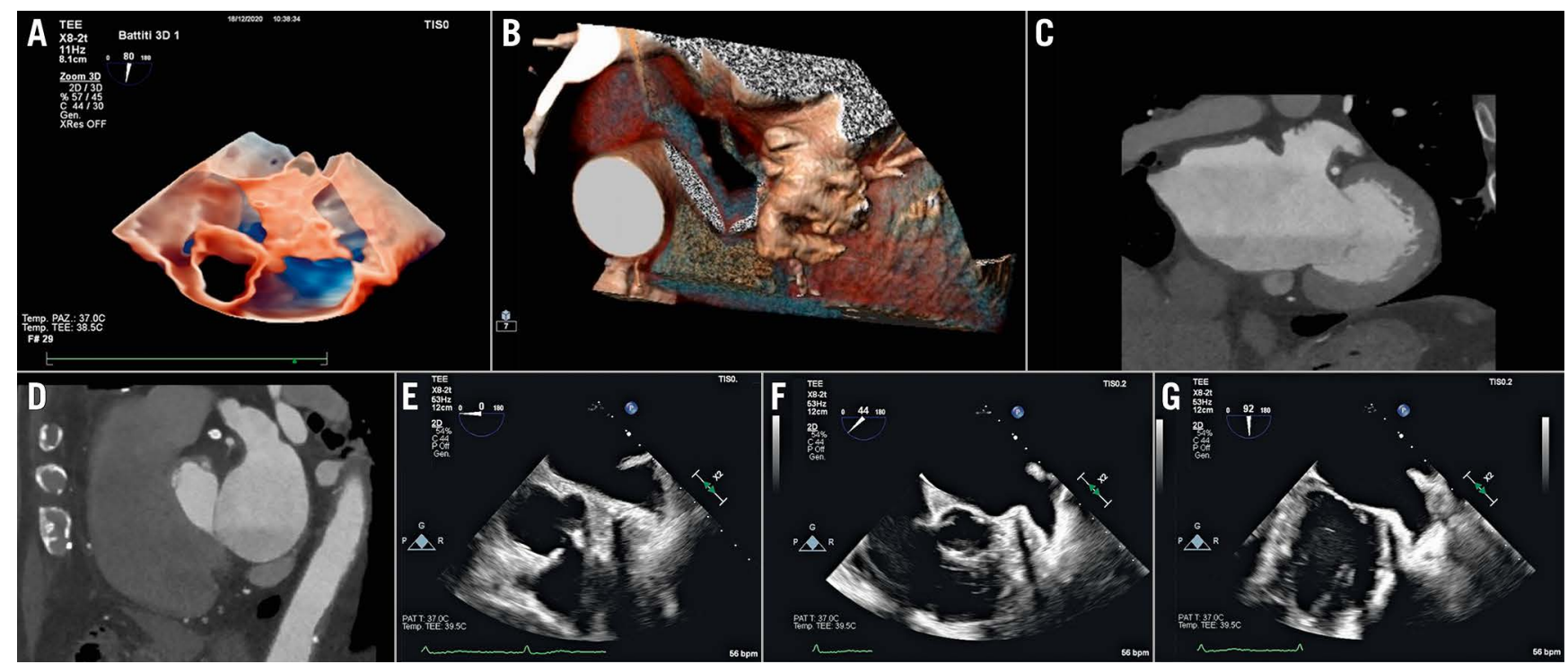

Figure 5. Recommended imaging modalities to evaluate the anatomy of the LAA. A) 3D TOE transparency rendering. B) $3 D$ CT volume rendering. C) CT coronal and sagittal (D) reconstructions. E-G) Set of $2 D$ TOE views ranging from 0-to-135 $5^{\circ}$ LAA: left atrial appendage; TOE: transoesophageal echocardiography

The sequential steps are described in Figure 7 and Supplementary Table 2.

TSP (performed as previously described) is required to access the LA. An inferior and posterior puncture site may normally facilitate the manoeuvres towards the LAA. However, a perfect alignment between the TSP needle and the LAA is desirable but not mandatory, as a correction of the trajectory is normally possible by manoeuvring the device delivery system. Entering the LA through a patent foramen ovale (PFO) is generally not advisable due to an unfavourable trajectory, thus the interventionalist should

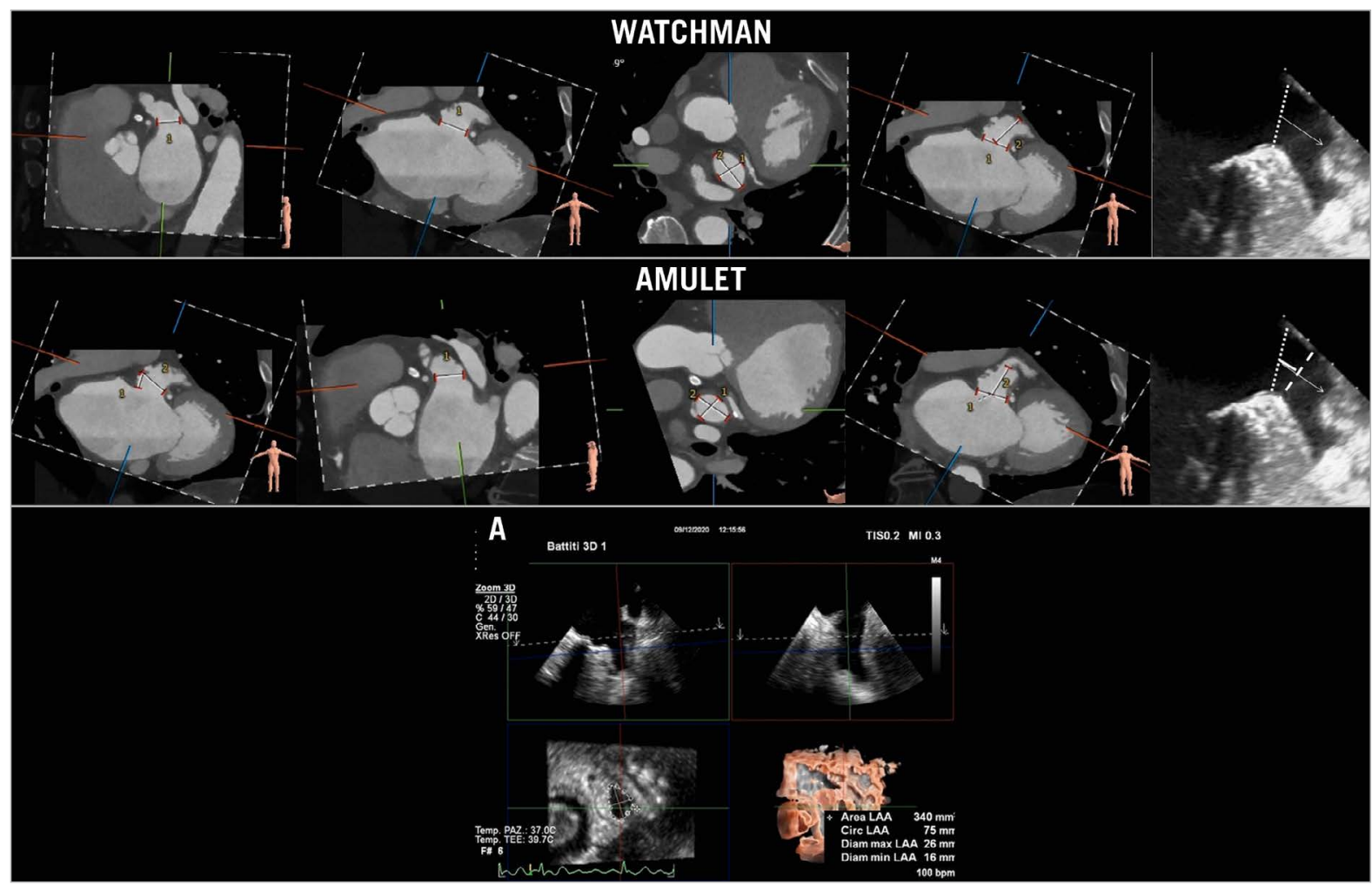

Figure 6. Recommended imaging modalities for LAA sizing. The WATCHMAN device (Boston Scientific) size is chosen based on the dimensions of the LAA ostium (dotted line in TOE view) and the depth of the appendage. For the AMPLATZER Amulet device (Abbott Laboratories), the device landing zone is $1 \mathrm{~cm}$ distally from the LAA ostium (dashed line in TOE view). A) 3D TOE semi-automated measurement of LAA sizing based on MPR algorithm. LAA: left atrial appendage; MPR: multiplanar reconstruction; TOE: transoesophageal echocardiography 


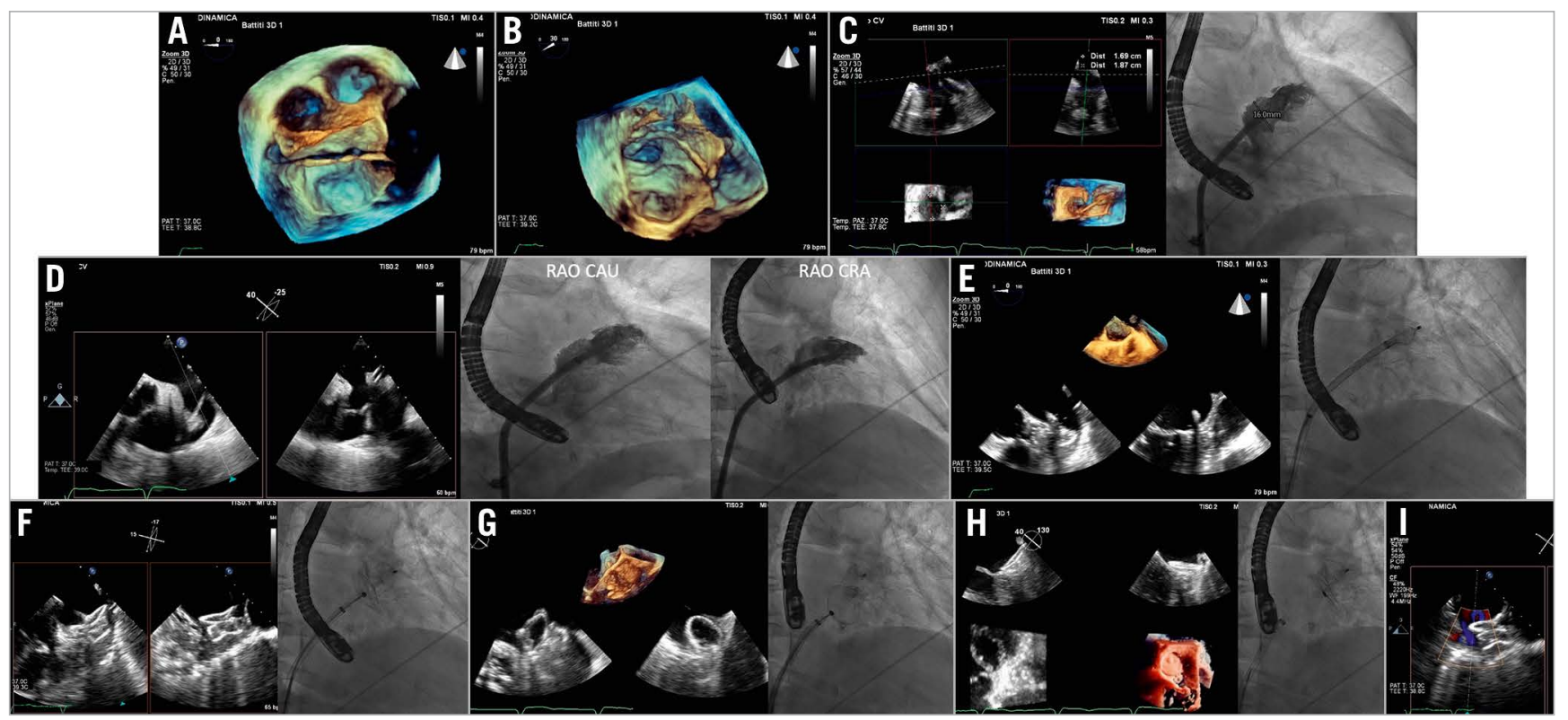

Figure 7. LAA closure procedural steps (AMPLATZER Amulet device). A) Navigation inside the LAA with wire and catheter (3D overhead of the LAA). B) LAA engagement by the wire ( $3 D$ en face view of LAA). C) Echocardiographic and angiographic LAA sizing. D) Implant projections: TOE views $0^{\circ}-60^{\circ}$ corresponding to RAO cranial view and $120^{\circ}-135^{\circ}$ corresponding to RAO caudal view. E) Lobe expansion. F) Disc opening. G) Tug test. H) Release and final result. I) Leak evaluation. CAU: caudal; CRA: cranial; LAA: left atrial appendage; RAO: right anterior oblique; TOE: transoesophageal echocardiography

be informed if PFO crossing is suspected. After access to the LA is obtained, the LAA can be angiographically imaged by power injections through the pigtail catheter.

For the subsequent manoeuvres of stiff guidewire and delivery sheath positioning, right anterior oblique (RAO) projections at approximately $40^{\circ}$ or RAO caudal (CAU) $20^{\circ}$ projection (usually the one that best depicts the LAA) is chosen.

After the device has been released, echocardiography allows checking for correct device placement according to devicespecific criteria. The residual leak in the LAA can be assessed with colour Doppler by lowering the Nyquist limit to $20-30 \mathrm{~cm} /$ $\sec ^{15}$. Conventionally, a jet flow $\geq 5 \mathrm{~mm}$ will be considered significant and might prompt device resheathing and repositioning ${ }^{15}$.

Fusion imaging seems helpful during all steps of the LAA occlusion procedure in terms of radiation exposure and fluoroscopy time and avoids continuous probe manipulation (Figure 8A-Figure 8C) (6,17. $^{16}$.

ICE provides intracavitary images of the LAA. From the baseline "home view", the probe can be manoeuvred posteriorly to image the IAS and guide the TSP. Although imaging the LAA with the ICE probe in the right atrium, coronary sinus, right ventricle or in the pulmonary artery is possible ${ }^{18}$, in order to obtain adequate pictures the ICE probe needs to be positioned in the LA. ICE can be introduced using two separate TSP punctures or, more often $^{19}$, if a single TSP technique is used, the delivery sheath is used to dilate the TSP and the ICE catheter is advanced in the LA along the stiff guidewire ${ }^{20}$. The LAA can then be imaged from various positions within the LA for procedural guidance (Figure 8D, Figure $\mathbf{8 E}$ ). If intraprocedural ICE is used and preprocedural TOE avoided, the patient should undergo preprocedural CT evaluation before the procedure for a completely TOE-free procedure.

\section{FOLLOW-UP}

The patient usually undergoes a TTE before discharge in order to check for possible complications such as pericardial effusion or mitral valve (MV) damage. The occluder device might be indirectly visualised inside the LA as a metallic artefact ${ }^{21}$. No consensus or guidelines are available regarding the imaging follow-up after an LAA closure procedure (modality and frequency). Usually, imaging follow-up is performed by TOE, however, CT is also useful for post-procedural surveillance ${ }^{22}$. Follow-up involves checking for the correct position of the device, the formation of atrial-side device residual leak (patency) into the LAA, device embolisation and pericardial effusion. It should be noted that CT appears more sensitive than TOE in detecting leaks after device implantation ${ }^{23}$.

\section{TRANSCATHETER MITRAL VALVE INTERVENTIONS}

Transcatheter mitral valve interventions (TMVI), either repairing or replacing the MV, are established alternative options for patients with mitral regurgitation (MR) who are not suitable for conventional open heart surgery. Available transcatheter therapeutic options are:

- Leaflet repair: an edge-to-edge repair procedure which mimics the surgical one by approximating MV leaflets together at the site of regurgitation.

- Chordal repair: adjustable transapical beating-heart artificial chordal implantation. 

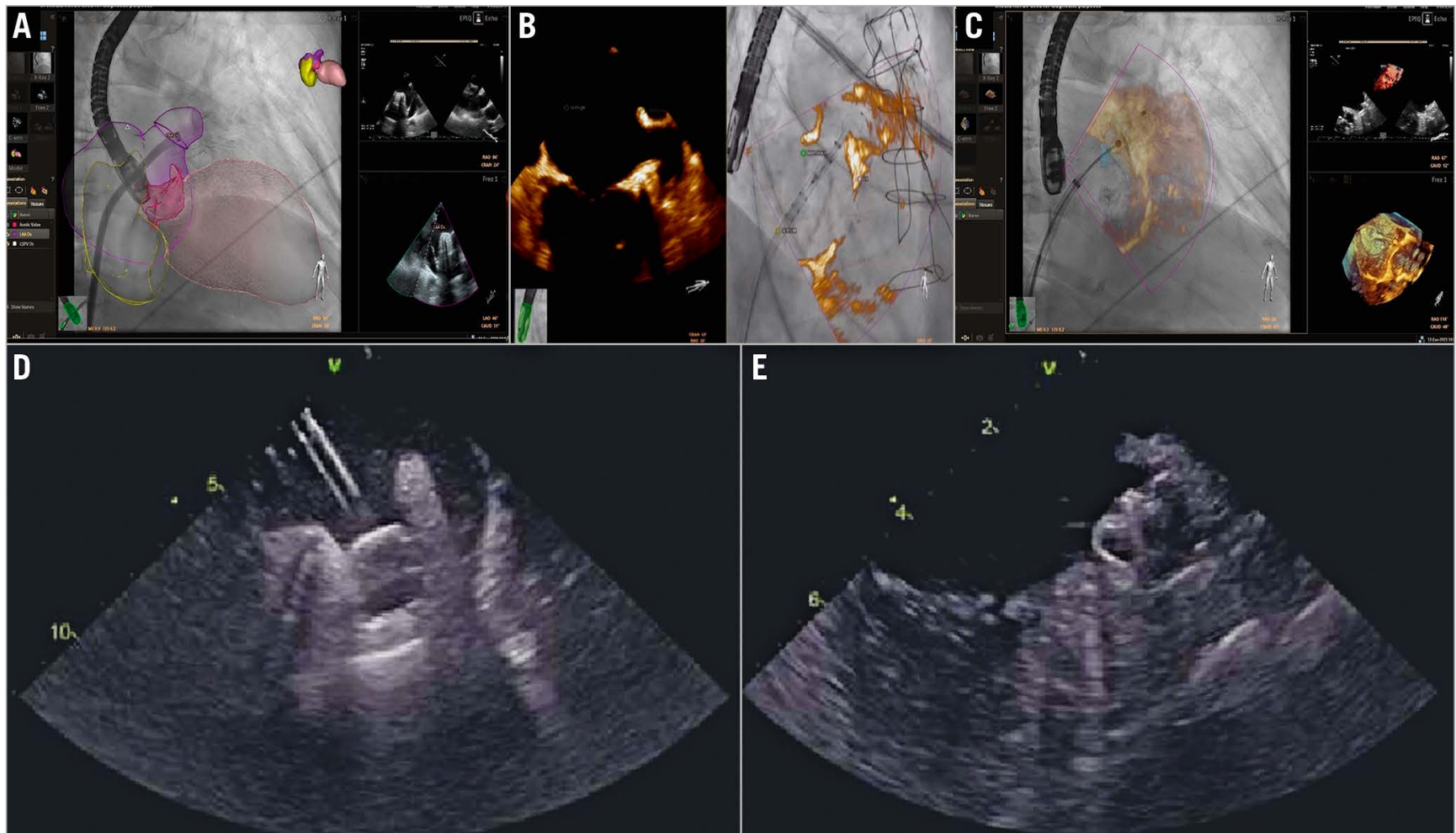

Figure 8. LAA closure procedural steps. A-C) Fusion imaging and D-E) ICE guidance. A) Heart model. Catheter inside the LAA. B \& C) LAA is displayed in $3 D$ rendering. B) Lobe expansion. C) Disc opening. D\& E) ICE guidance during LAA occlusion. The ICE probe in the left atrium is showing the device on the delivery cable (D) and the device in its final position (E). ICE: intracardiac echocardiography; LAA: left atrial appendage

- Annular repair: percutaneous direct or indirect annuloplasty aiming to reduce annular dimensions and improve leaflet coaptation.

- MV replacement.

\section{PREPROCEDURAL EVALUATION}

Preprocedural evaluation aims to evaluate MR severity and the functional anatomy of the MV in order to choose the best therapeutic option. In particular, leaflet repair is mainly indicated in functional MR due to leaflet tethering or degenerative MR, chordal implantation in patients with leaflet prolapse, annuloplasty devices for functional MR due to annular dilatation and, in case of complex mechanisms not suitable for MV repair, MV replacement may be an alternative option ${ }^{24}$.

TTE is the first-line imaging technique to rule out potential candidates for percutaneous intervention. In case of possible suitability for TMVI, TOE is mandatory to evaluate carefully the $\mathrm{MV}$ anatomy and the mechanism of regurgitation. In addition, for therapeutic approaches targeting the annulus, and for MV replacement, CT evaluation is mandatory for annular sizing and evaluating morphological characteristics in terms of calcifications, spatial relationships with surrounding structures, and the risk of left ventricular outflow tract (LVOT) obstruction.

\section{TRANSCATHETER LEAFLET APPROXIMATION}

Two devices are currently available: MitraClip (Abbott Laboratories) and PASCAL devices (Edwards Lifesciences).
Echocardiographic assessment of functional anatomy and determination of the mechanism of MR are mandatory for patient selection. Based on the morphologic characteristics of the MV, we may identify potential candidates for edge-to-edge MV repair with different favourable/unfavourable features (Supplementary Table 3).

\section{PROCEDURAL STEPS AND IMAGING GUIDANCE}

Under general anaesthesia, echocardiography and fluoroscopy guide the procedural steps (Figure 9, Figure 10, Supplementary Table 4).

1. The TSP needs to be tailored to the procedure: usually it should be in the inferior-posterior aspect of the fossa ovalis. Moreover, lower TSP sites are required for lateral regurgitant jets, while higher ones are needed for medial jets in order not to fall below the MV when deflecting the system. The guide catheter is then inserted into the LA. Disappearance of tenting on the IAS is an indicator of complete crossing: the dilator can be removed when the guide catheter is at least $2 \mathrm{~cm}$ across the IAS. Afterwards, the delivery system is advanced into the LA.

2. The system is then steered towards the MV over the target lesion. The trajectory should ensure perpendicularity to the MV plane: misalignment can affect both the symmetry and efficacy of the grasping.

3. Perpendicularity is usually guided in biplane imaging (commissural and long-axis view) and should be achieved in both views. 


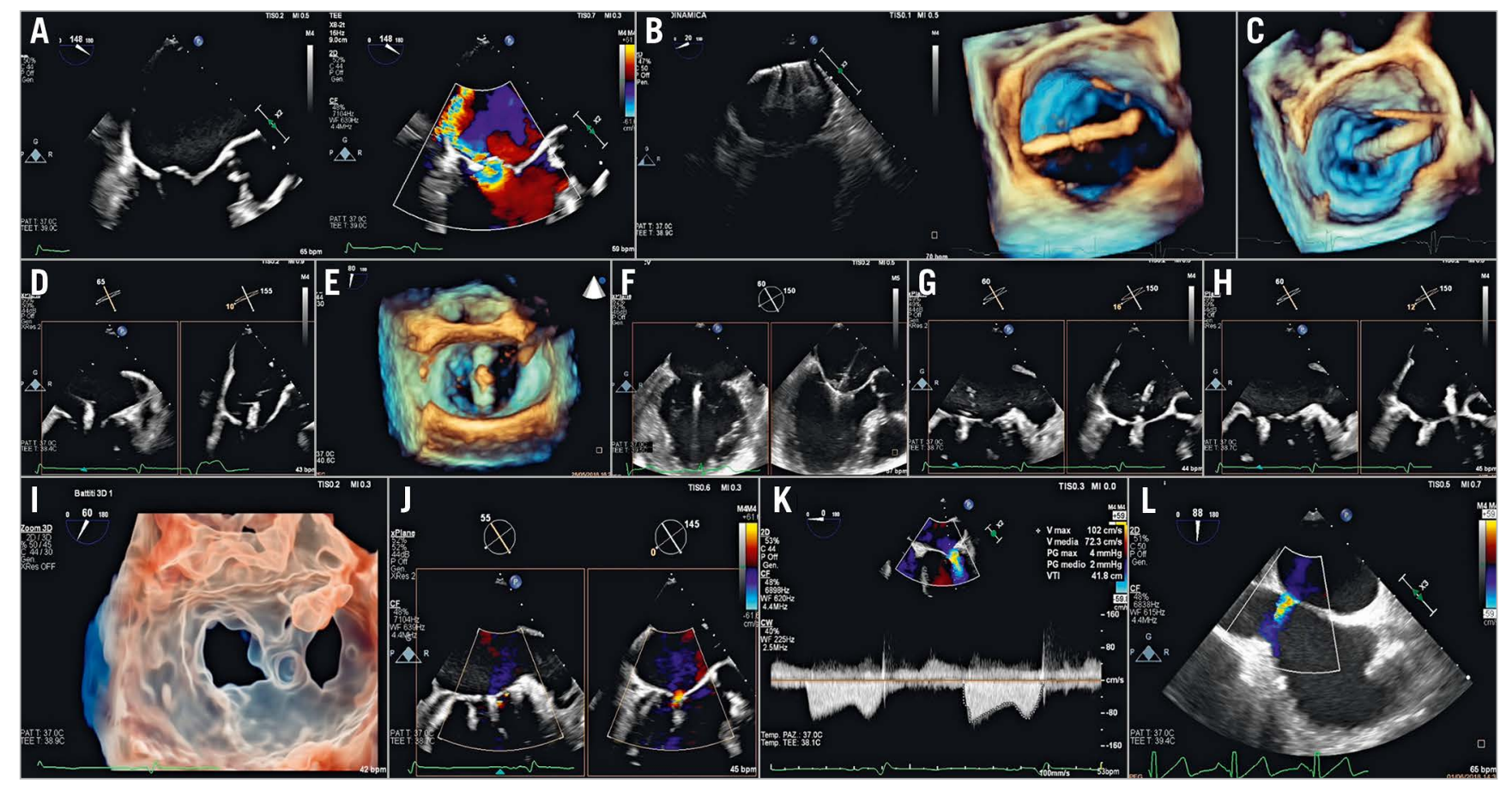

Figure 9. MitraClip procedural steps. A) Baseline evaluation. B) Clip extrusion into the LA. C) Steering of the CDS towards the MV plane. D) Trajectory. E) Clip arm orientation. F) Clip advancement into the LV and leaflet grasping. G) Assessment of leaflet insertion. H) Clip release. I) $3 D$ transparency rendering en face view of the $M V$ showing the double orifice clearly. J) Final result. K) Transmitral gradient. L) Residual ASD evaluation. ASD: atrial septal defect; CDS: clip delivery system; LA: left atrium; LV: left ventricle; MV: mitral valve

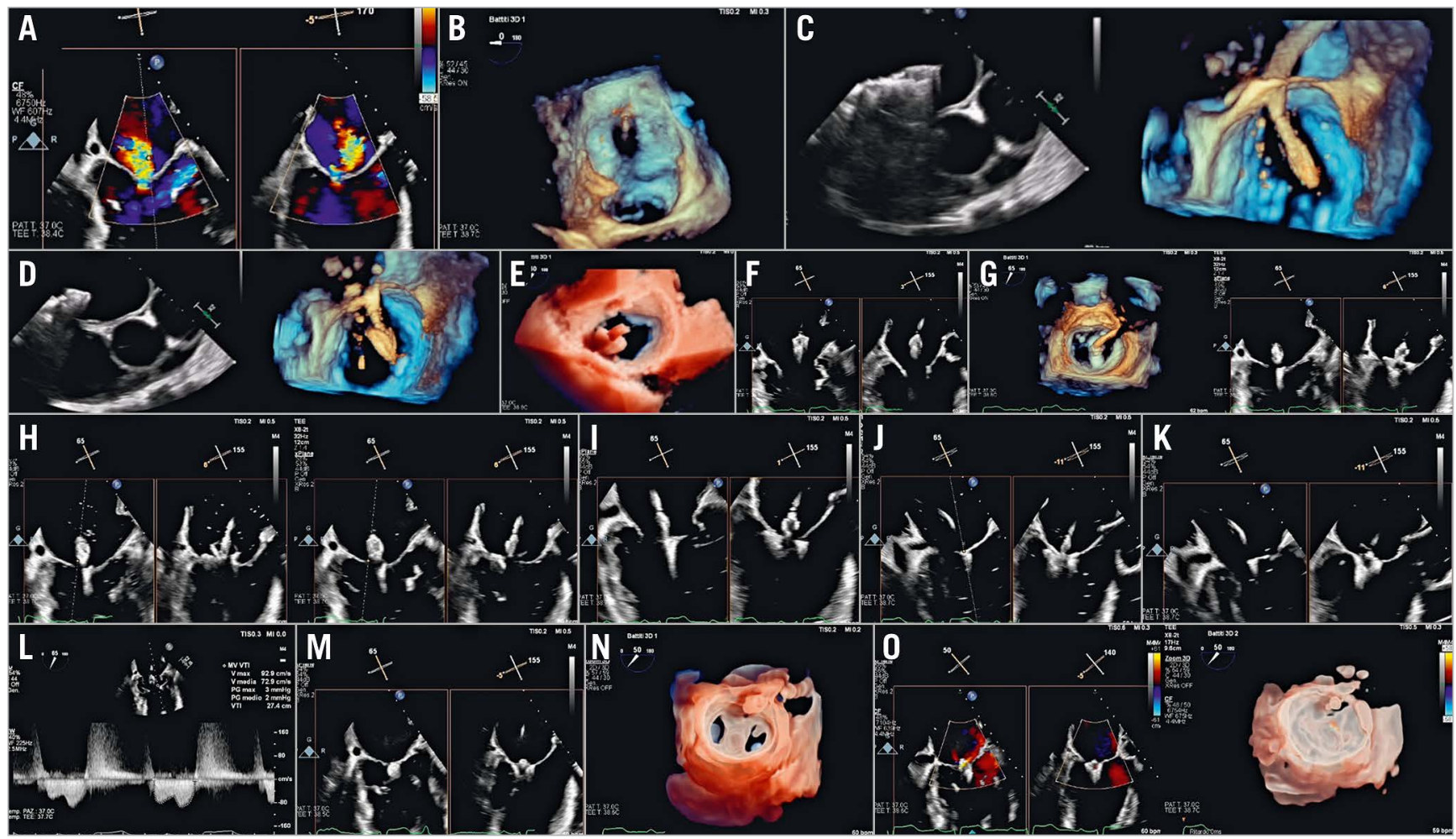

Figure 10. PASCAL procedural steps. A) Baseline evaluation. B) Parallelism test to ensure guide sheath tip flexes parallel to MV (3D en face view of the septum). $C \& D$ ) implant system insertion: (C), implant elongated, and (D), implant closed. E) Steering towards the MV plane. F) Implant trajectory and positioning. G) Implant orientation. H) Identification of anterior and posterior clasp. I) Crossing valve. J) Leaflet capture. K) Implant closing. L) Transmitral gradient. M) Implant release. N) 3D transparency rendering en face view of MV showing the double orifice clearly. O) Post-implant release evaluation. MV: mitral valve 
Once the appropriate axial alignment is achieved over the target lesion, the device arms are opened and oriented perpendicularly to the coaptation line.

4. The system is then advanced below the MV with arms partially open $\left(60^{\circ}\right)$ and with the paddles fully open in the MitraClip and PASCAL procedure, respectively. Once below the MV plane, the arms are fully opened, and correct positioning and orientation is rechecked as the implant may rotate when crossing the MV. Inside the left ventricle (LV), any needed changes in the orientation of the arms should be minimal; in case of significant orientation adjustment, the device should be inverted and withdrawn back into the LA. By retracting the system back, once both leaflets are visualised over the arms, the grippers are lowered down and leaflets grasped. If the implant appears properly positioned, the implant can be fully closed.

5. Adequate leaflet insertion is evaluated by direct and indirect signs. The best result should be a balance between iatrogenic stenosis and adequate reduction of MR, without distortion of the coaptation line. An MV area $\leq 1.5 \mathrm{~cm}^{2}$ and a transmitral pressure gradient $>5 \mathrm{mmHg}$ indicate significant mitral steno$\operatorname{sis}^{25}$. Once the result is satisfactory, the device is detached from the delivery system.

The evaluation of residual MR after edge-to-edge is very challenging. The evaluation of residual MR should be performed under haemodynamic conditions similar to baseline using a multiparametric approach and classified in a 4-grade system $(1+\text { to } 4+)^{26,27}$ (Supplementary Table 5).

6. After release of the device, the delivery catheter is withdrawn into the guide catheter, which is maintained in the LA, as a second clip implantation may be required. If no additional clip is needed, the system can be removed. After system removal, the residual shunt and size of iatrogenic atrial septal defect (ASD) should be evaluated. The defect is usually clinically insignificant ${ }^{28}$.

TOE is fundamental to recognise complications promptly, e.g., intracardiac thrombosis on devices, cardiac tamponade, worsening of MR (leaflet or chordal damage, loss of leaflet insertion or partial clip detachment) and iatrogenic mitral stenosis.

ICE could be an alternative imaging tool in case of contraindication to TOE, although experience is limited ${ }^{29}$. TSP guidance may be performed with the catheter in the right atrium, while the remaining procedural steps require the position of the catheter in the mid-right ventricle and the outflow tract. ICE images allow good visualisation especially of the central portion of the valve and they are useful to detect complications.

Although this procedure is effectively guided by $2 \mathrm{D} / 3 \mathrm{D}$ TOE and fluoroscopy, echocardiographic-fluoroscopic fusion imaging may potentially have additional value (Figure 11$)^{30-32}$. Fusion imaging may be helpful in:

- Guiding TSP

- Navigating into the LA

- Assessing device trajectory and alignment

- Co-localising the regurgitant jet

\section{TRANSCATHETER ANNULOPLASTY}

\section{DIRECT ANNULOPLASTY}

The Cardioban device (Edwards Lifesciences) is an incomplete adjustable surgical-like Dacron band, transseptally delivered, implanted on the posterior annulus from the anterolateral to posteromedial commissure.

The procedure is heavily dependent on pre-interventional screening based on echocardiography and CT scan, in order to assess: (i) technical feasibility, based on the relationship between circumflex artery and posterior annulus; (ii) annulus sizing and thickness; and (iii) the anatomy of the LA and IAS. Preprocedural CT also provides the coordinates for the procedure and the expected fluoroscopic projections.

\section{INTRAPROCEDURAL MONITORING}

The optimal site for the TSP is predefined by CT planning, providing distances from the muscular part, from the aorta, and the height measured from the annular plane ( $>3.5 \mathrm{~cm}$ from the annular plane). The puncture site must be straight above the posteromedial commissure.

The sequential steps are described in Figure 12, Supplementary

\section{Table 6.}

The steering and navigation of the implant delivery system along the posterior annulus is guided by different 3D perspectives and the fluoroscopic LAO CAU view. After reaching the target point, RAO projection, several 2D and biplane views or MPR are used to assess the proper distance from the hinge point of the posterior leaflet and the device angulation for fine adjustment, and for checking proper anchoring via a push-and-pull test. Coronary angiography rules out the risk of injury to the circumflex artery.

The first anchor should be positioned as anterior as possible and close to the anterolateral trigone. The Cardioband implant is navigated to the next anchoring point along the posterior annulus until it reaches the posterior trigone. After the last anchor deployment and disconnection of the device, the size adjustment tool is inserted and connected to the spool of the implant, that is then contracted while reduction of MR severity and annulus size are monitored.

A multiparametric approach provides the most appropriate method to characterise and quantify residual MR, the possible iatrogenic stenosis, and the mitral annular remodelling.

Fusion imaging may be helpful in the different procedural steps: - TSP

- Navigation within the LA - the perimeter of the annulus is visible on the fluoroscopy

- Implant deployment - correct orientation of the catheter with respect to the annular plane and its position in relation to the leaflets hinge - relationship between tissue, anchors and coronary artery

- Implant size adjustment/cinching - modification of annular size taking into account both the reduction of the distance among the radiopaque anchors and the reduction of the annular tissue 


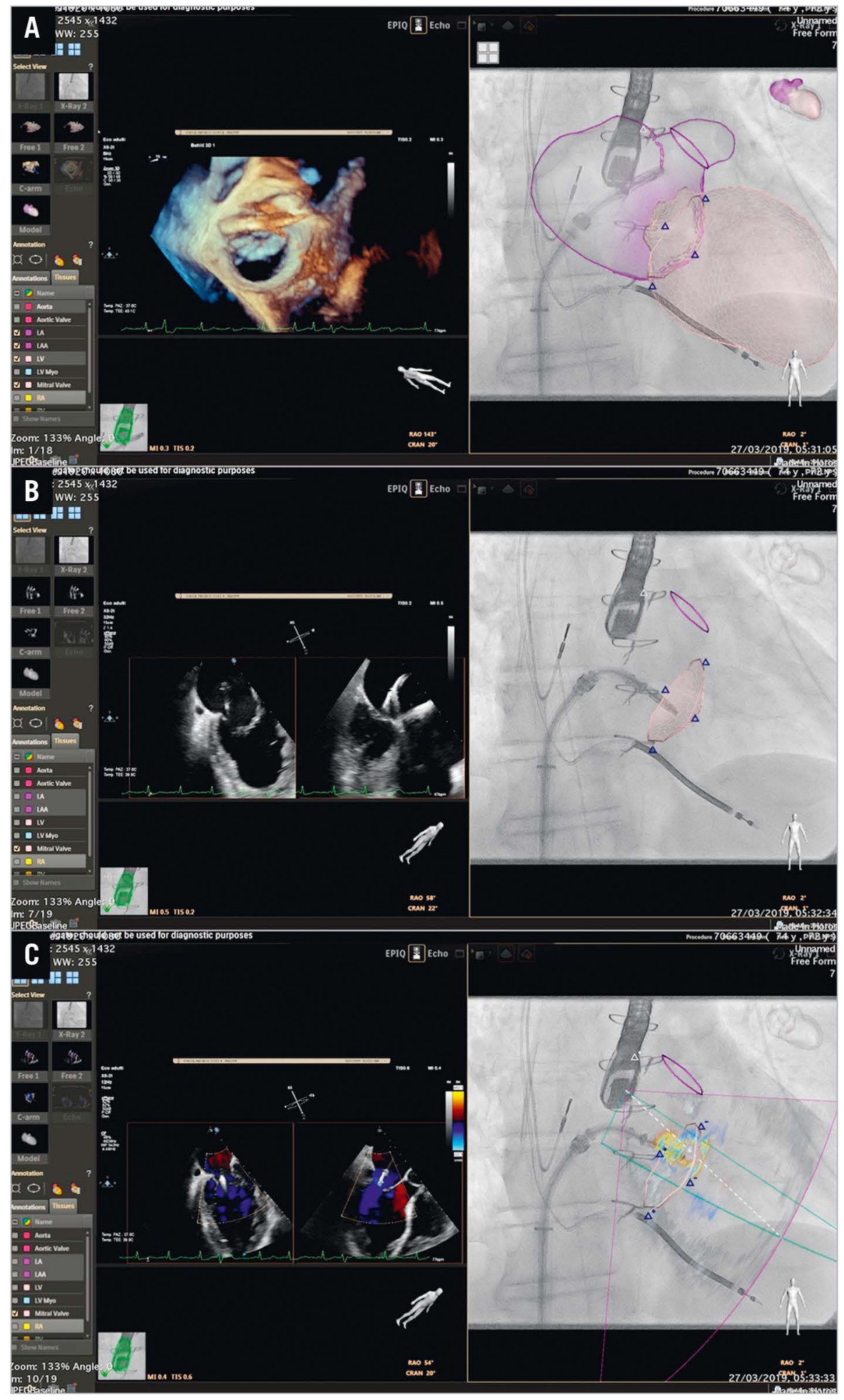

Figure 11. Fusion imaging with heart model in the MitraClip procedure-essential steps. A) Navigation into the LA. B) Steering and positioning the DC towards the MV.C) The jet is displayed on the fluoroscopic screen and used as a reference marker (target lesion).

\section{TRICUSPID TRANSCATHETER INTERVENTIONS}

\section{INDICATIONS}

Tricuspid regurgitation (TR) is a frequent finding on routine echocardiography. In the Framingham Heart Study it was present in more than $80 \%$ of the cohort ${ }^{33}$. The prevalence of more than moderate TR increases with ageing, reaching up to $1.5 \%$ in men and $5.6 \%$ in women over seventy. A mild degree is considered benign, but moderate and severe TR are associated with worse outcome. 

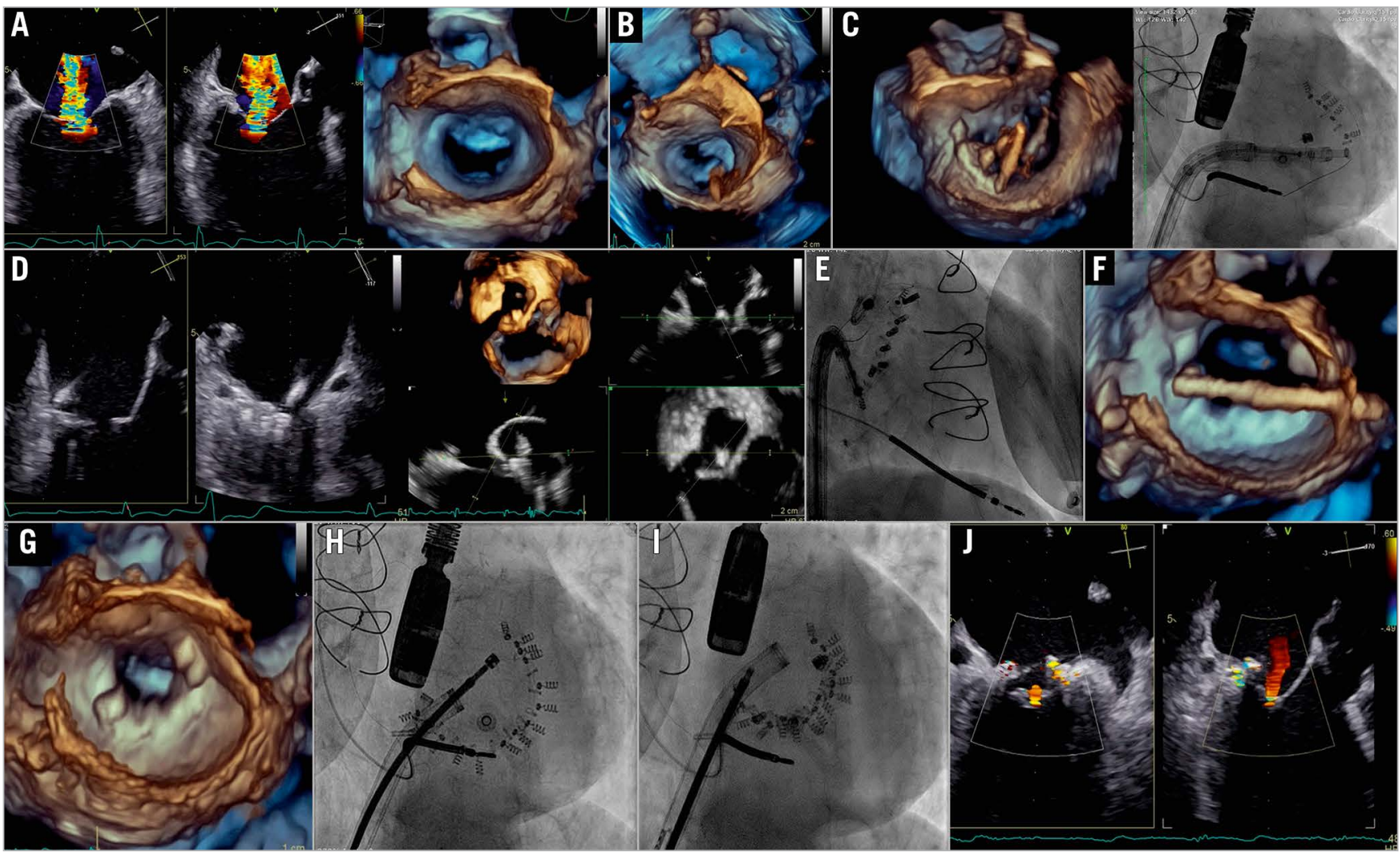

Figure 12. Cardioband procedure in the mitral valve. A) Baseline evaluation. B) TSP: overhead perspective of the LA showing tenting with respect to the posteromedial commissure. C) System navigation around the target zone guided by $3 D$ perspectives and LAOCAU fluoroscopic projection. D) Visualisation of the contact of IC with the annulus by biplane view and MPR. E) RAO projection used for implant and pull test. F) Size adjustment tool (SAT) insertion. G) 3D en face view of MV after SAT removal showing the implant as an incomplete surgical annuloplasty. H) LAO before cinching. I) After cinching. J) Final result. IC: implant catheter; LA: left atrium MPR: MV: mitral valve; TSP: transseptal puncture

The optimal timing of intervention remains unclear, although it should be carried out sufficiently early to avoid irreversible right ventricular (RV) dysfunction ${ }^{34}$.

In severe primary $\mathrm{TR}$, surgery is not only recommended in symptomatic patients but also in asymptomatic patients when progressive RV dilatation or decline in RV function occurs. In severe secondary TR, tricuspid repair during left-sided surgery has been demonstrated to provide reverse RV remodelling and improvement of functional status. To improve the prognosis, the treatment of severe late TR following left-sided valve surgery should be considered earlier, even in asymptomatic patients, if there are signs of progressive RV dilatation or decline in RV function.

Surgical tricuspid valve (TV) annuloplasty is the gold standard in many cases. Although well-established risk models exist for several other cardiac operations, no well-established risk model exists for the performance of isolated TV operations. The only available score has been proposed by LaPar et $\mathrm{al}^{35}$, who developed parsimonious clinical risk models for operative mortality and major morbidity after isolated TV operations. The factors most strongly associated with mortality include preoperative haemodialysis requirement, advanced lung disease, NYHA Functional Class and performance of emergent operations, highlighting the central clinical message that early referral for the performance of TV operations has the potential to reduce surgical mortality and morbidity for these patients ${ }^{35}$.

Several transcatheter techniques are currently in bench and early clinical testing as alternative options. The number of patients treated with these techniques is still limited and data on long-term outcomes are missing. Current studies aim to address the question of whether interventional TR treatment provides an alternative option for patients with severe functional TR, refractory symptoms of RV failure and prohibitive surgical risk.

\section{PREPROCEDURAL EVALUATION}

Multimodality imaging is essential for patient selection as well as procedural planning, with a systematic approach for identifying the mechanism and severity of TR, as well as for determining the suitability of catheter-based interventional therapies. The three TV leaflets cannot be visualised simultaneously with 2D echocardiography, and therefore, $3 \mathrm{D}$ echocardiography is recommended to completely evaluate the $\mathrm{TV}^{36}$.

TTE is the first-line imaging test for evaluating the TV. Due to the anterior location of the valve, its transthoracic visualisation is of good quality. 
With a view to repairing TR with a transcatheter therapy, it is important to grade the TR severity. In advanced TR there are more degrees of severity than the guidelines describe. Therefore, alternative grading schemes with expansion of the "severe" grade have been described to quantify more accurately baseline TR severity, prognosis and the response to treatment ${ }^{37}$.

TOE may provide additional information ${ }^{38}$. Multiple acoustic windows acquired from several depths and plane angles, along with the use of simultaneous biplane imaging, are needed to completely visualise the $\mathrm{TV}^{39}$ (Supplementary Table 7).

Standardisation of the TV 3D image display is essential to facilitate communication between the echocardiographer and the interventional cardiologist. In the "en face perspective" of the TV, the valve should be oriented with the aortic valve at the 10 o'clock position and the inferior vena cava at the $7 \mathrm{o}^{\prime} \mathrm{clock}^{40}$.

After echo screening, CT is mandatory for patient selection and procedural planning for specific procedures (annuloplasty and replacement). This allows accurate measurement of the TV annulus, device landing zone, relationship between the annulus and the right coronary artery, and annular tissue quantity and quality.

Patients with severe leaflet tethering are too advanced and may not benefit from TV surgical annuloplasty repair. The surgical experience of valve repair has shown that factors associated with failed annuloplasty are a tenting height $\geq 0.8 \mathrm{~cm}$, a tenting volume $\geq 2 \mathrm{~cm}^{3}$ and a tenting area $\geq 1.8 \mathrm{~cm}^{2}$. In a similar way, a coaptation depth $<10 \mathrm{~mm}$, a central or anteroseptal jet location, as well as a coaptation gap of less than about $7 \mathrm{~mm}$ have been identified as independent predictors of procedural success for transcatheter interventions. In addition, reduction of TR of less than one grade and elevated pulmonary pressures are independent predictors of mortality ${ }^{41}$. Pulmonary hypertension $(\mathrm{PH})$ frequently coexists with severe TR and is associated with more severe right and LV heart failure and a higher preoperative risk. Echocardiographic assessment of pulmonary artery pressure (PAP) is of limited diagnostic value for the presence of $\mathrm{PH}$. In fact, sensitivity and specificity to accurately detect invasively confirmed $\mathrm{PH}$ in patients with severe TR are low ${ }^{42}$. Patients with both invasively and echocardiographically detected PH had similar outcomes to patients without invasive $\mathrm{PH}$ in terms of hard clinical endpoints, whereas invasive $\mathrm{PH}$ and a false negative echocardiographic PH had the worst outcomes $^{42}$. Moreover, evaluation of a pulmonary haemodynamic profile further stratifies the risk of patients undergoing transcatheter intervention ${ }^{42}$. The risk for mortality is only moderately increased in patients with postcapillary $\mathrm{PH}$ compared to patients without $\mathrm{PH}^{43}$. In contrast, a significant precapillary contribution to $\mathrm{PH}$ was demonstrated to be a high-risk constellation and was associated with increased mortality after a transcatheter approach ${ }^{43}$. On the basis of these findings, patients categorised into the postcapillary $\mathrm{PH}$ group benefit from transcatheter intervention ${ }^{43}$. In contrast, patients with a significant precapillary contribution to $\mathrm{PH}$ require different or complementary therapeutic strategies to a transcatheter approach ${ }^{43}$. Finally, patients with increased RV stroke work seem to be at higher risk of mortality after a transcatheter approach ${ }^{43}$.

There are different transcatheter treatment options. The selection of the device is based on the severity of annular dilation, jet location, leaflet tethering and retraction, as well as TOE imaging quality. Patients with predominant annular dilation and reasonable leaflet tethering are theoretically the best candidates for either an annuloplasty device (Cardioband or Tricinch [4TECH Cardio Ltd.]) or leaflet approximation systems ${ }^{44-46}$. Annuloplasty might be preferred for treatment of a central jet, while leaflet approximation is a good option for commissural TR. Patients presenting with very advanced RV remodelling, severe leaflet tethering/retraction or large coaptation gap may be evaluated for replacement ${ }^{46}$. Good quality TOE transgastric views are a prerequisite for candidacy for a leaflet approach.

\section{PROCEDURAL GUIDANCE}

Transcatheter tricuspid interventions are always performed under fluoroscopic and TOE guidance. If a suboptimal acoustic window is detected during procedural planning, multimodality imaging combining TTE, TOE and ICE should be considered to ensure the best quality intraprocedural guidance ${ }^{40,47}$

\section{DIRECT ANNULOPLASTY}

During the implantation of annuloplasty devices, it is essential to visualise the annulus. The best TOE planes are the mid-oesophageal view (at $90^{\circ}$ ), the deep oesophageal view (at $0^{\circ}$ ), and the transgastric view (at $0^{\circ}$ with simultaneous biplane imaging). For Cardioband implantation, TOE is essential to identify the angulation between the anchors and the annulus (as the implant of the anchors must be perpendicular) and the muscular tissue where the screw is implanted (Figure 13, Supplementary Table 8). The result is measured by the reduction of the tricuspid annulus and the TR.

\section{LEAFLET APPROACH}

The rationale behind TV leaflet approximation (TriClip [Abbott Laboratories] and PASCAL systems) is to restore coaptation between leaflets and reduce the regurgitant orifice area. The procedural steps and imaging guidance are shown in Figure 14-Figure 16 and Supplementary Table $\mathbf{9}$.

Assessing the results using echocardiography can be challenging, especially when multiple TR jets are created ${ }^{47}$. Theoretically, only the proximal isovelocity surface area (PISA) method, the volumetric methods and the $3 \mathrm{D}$ vena contracta area are appropriate for the quantitative evaluation of multiple regurgitant orifice by summation. Additionally, useful findings are the presence of changes of the hepatic vein flow patterns.

CT-fluoroscopy fusion imaging is another useful tool for assessment of eligibility for tricuspid transcatheter interventions and it can also serve as a guide to determine the optimal site. It provides an interesting tool for procedural planning and guidance ${ }^{39}$. 

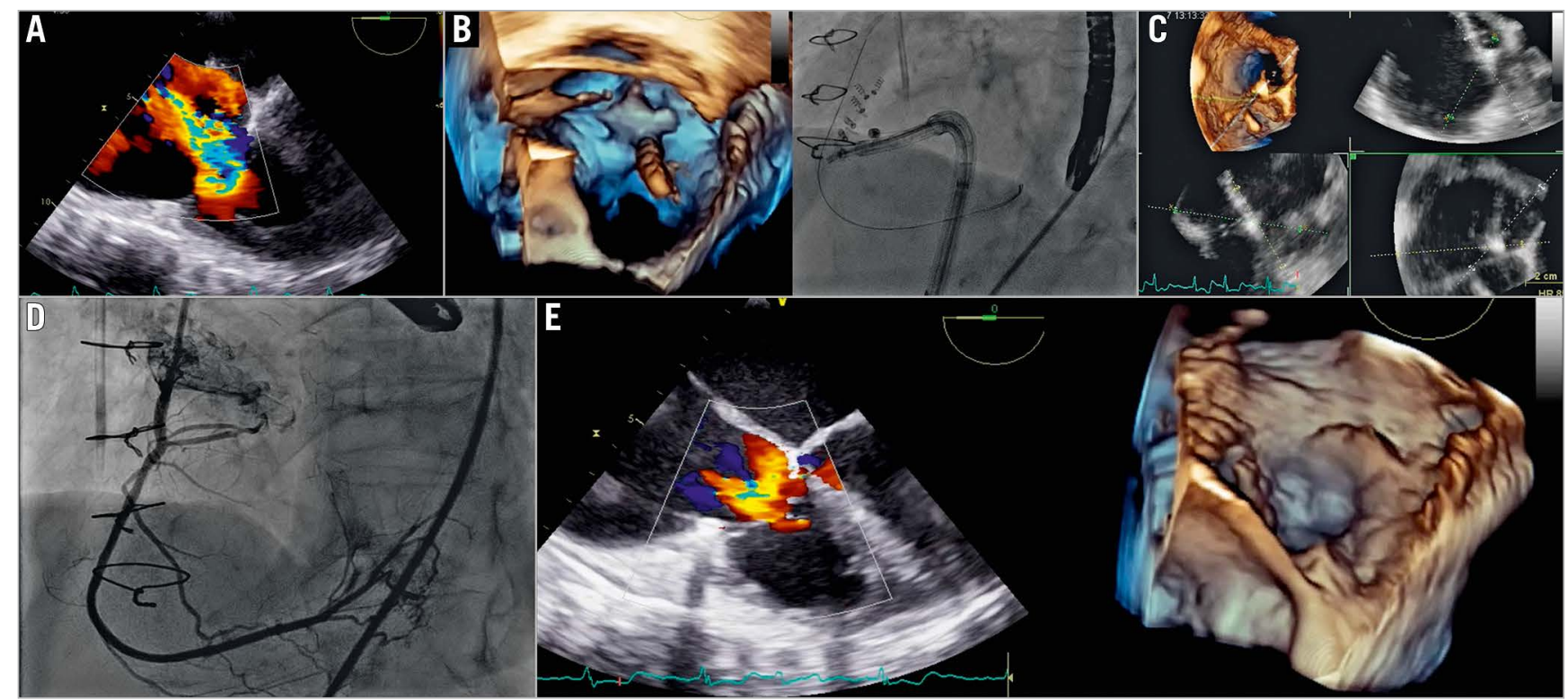

Figure 13. Cardioband procedure in the tricuspid valve. A) Baseline evaluation. B) Navigation of delivery system along the tricuspid annulus. C) $3 D M P R$ for fine evaluation of the delivery catheter on the annulus. D) Right coronary angiography to assess injury of the RCA during anchor implantation. E) Final result. MPR: multiplanar reconstruction; RCA: right coronary artery

\section{PATENT FORAMEN OVALE AND ATRIAL SEPTAL DEFECT CLOSURE}

PFO is a common finding affecting approximately $25 \%$ of the general population ${ }^{48}$. In some patients it may, however, have a pathophysiologic role in causing cryptogenic stroke, migraine or hypoxaemia due to right-to-left shunting ${ }^{49-53}$.

Correct identification and description of a right-to-left shunt across a PFO is mandatory before percutaneous closure is attempted.

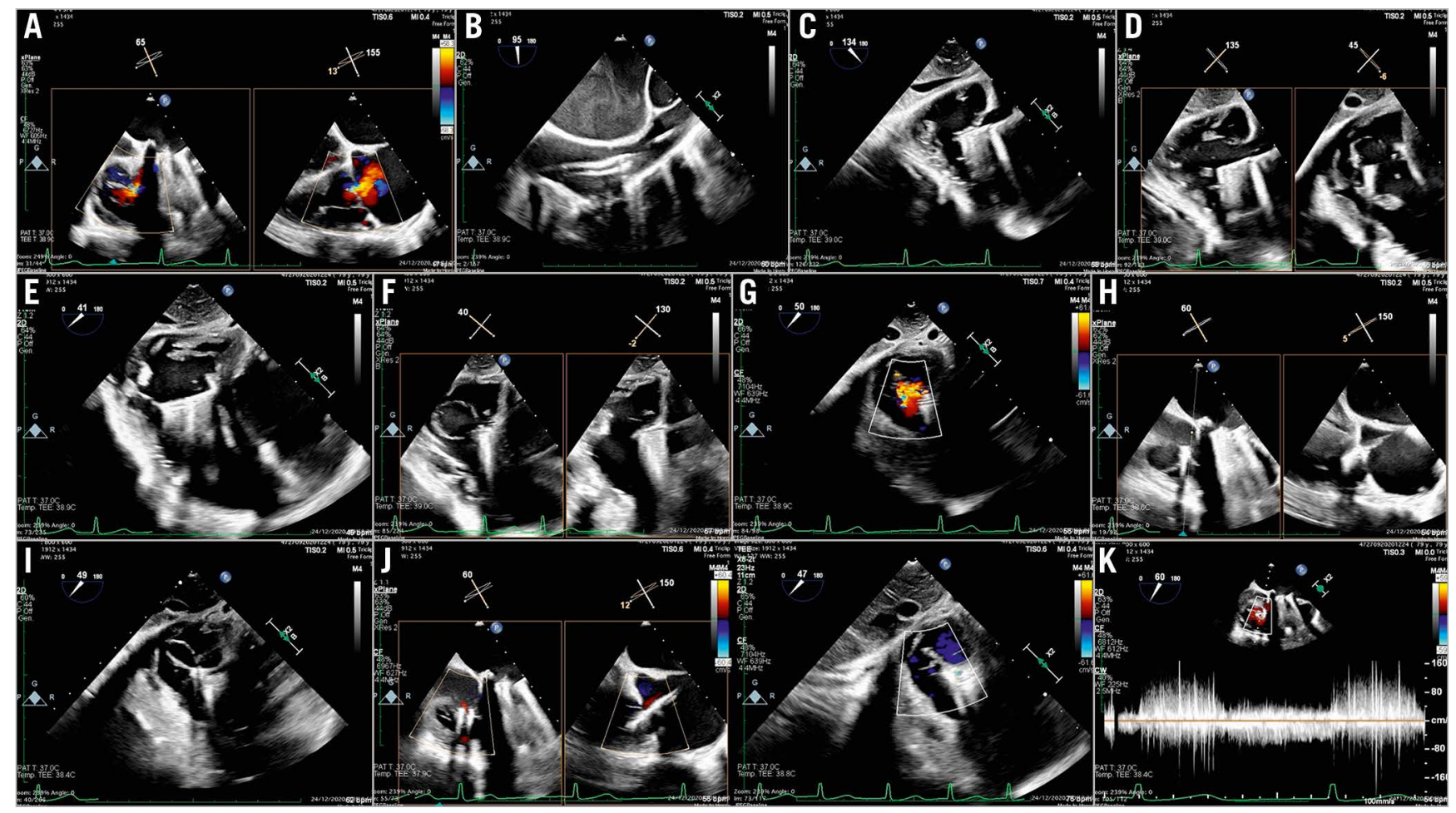

Figure 14. TriClip procedure. A) Baseline evaluation. B) GC insertion into the RA. C) Steering manoeuvre towards the TV plane and trajectory (LAX transgastric view). D) CDS advancement into the RV (biplane transgastric views). E) Clip arm orientation (SAX transgastric view). F) Leaflet grasping. G) Residual TR after first clip implantation (SAX transgastric view). H) Assessment of leaflets insertion. I) Second clip implantation. J) Result after second clip. K) Transvalvular gradient. CDS: clip delivery system; GC: guide catheter; RA: right atrium; $R V$ : right ventricle; $S A X$ : short axis; TR: tricuspid regurgitation 


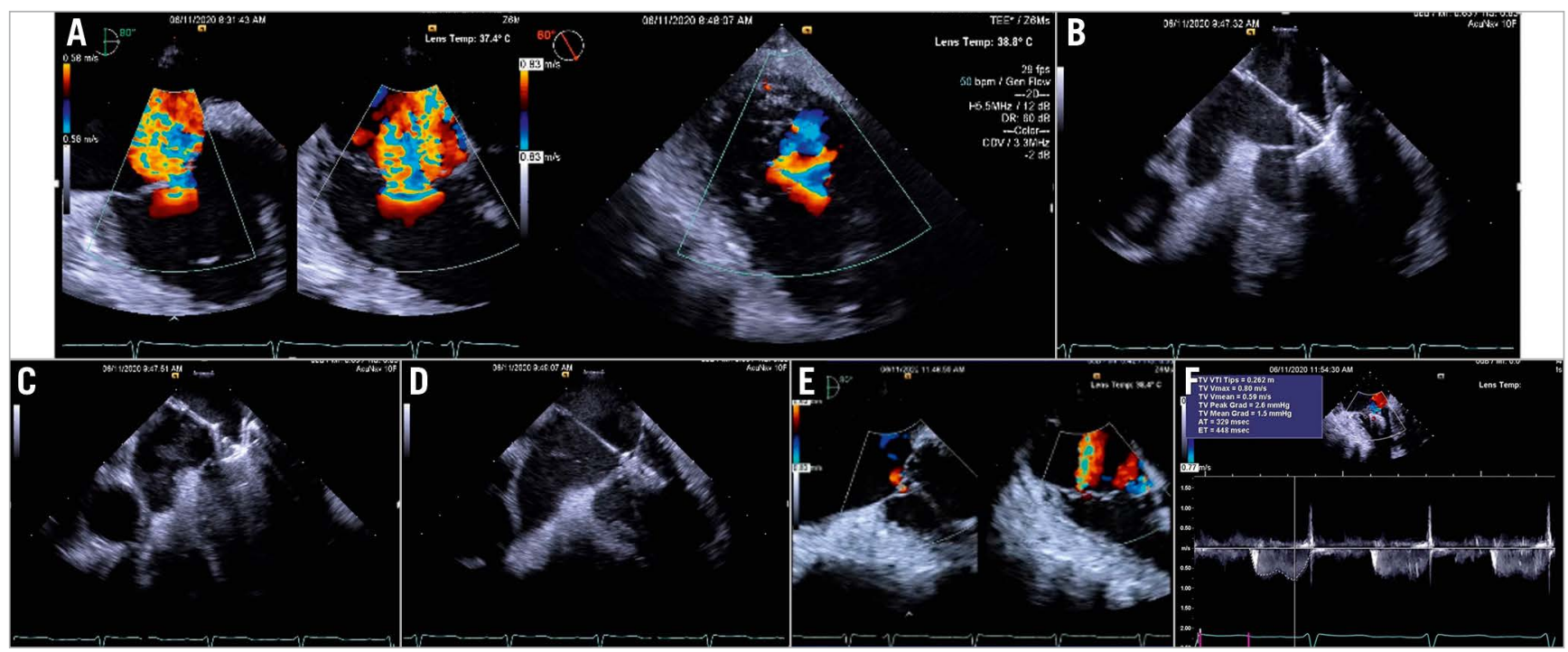

Figure 15. TriClip procedure guided by ICE. A) Baseline evaluation. B) Clip advancement into the RV. C) Leaflet grasping. D) Assessment of leaflet insertion. E) Final result. F) Transvalvular gradient. Courtesy of Mani Vannan, Marcus Heart Valve Center, Piedmont Heart Institute, Atlanta, USA. MV: mitral valve

Contrast-enhanced transcranial Doppler (TCD) or contrast-enhanced TTE are common first-line examinations that carry a sensitivity of $94 \%$ and $88 \%$, respectively, and a specificity of $92 \%$ and $82 \%$, respectively ${ }^{54}$.
According to a recent European position paper on PFO closure, contrast-enhanced TCD should be performed in case of a negative or equivocal contrast $\mathrm{TTE}^{55}$. If a right-to-left shunt is confirmed,

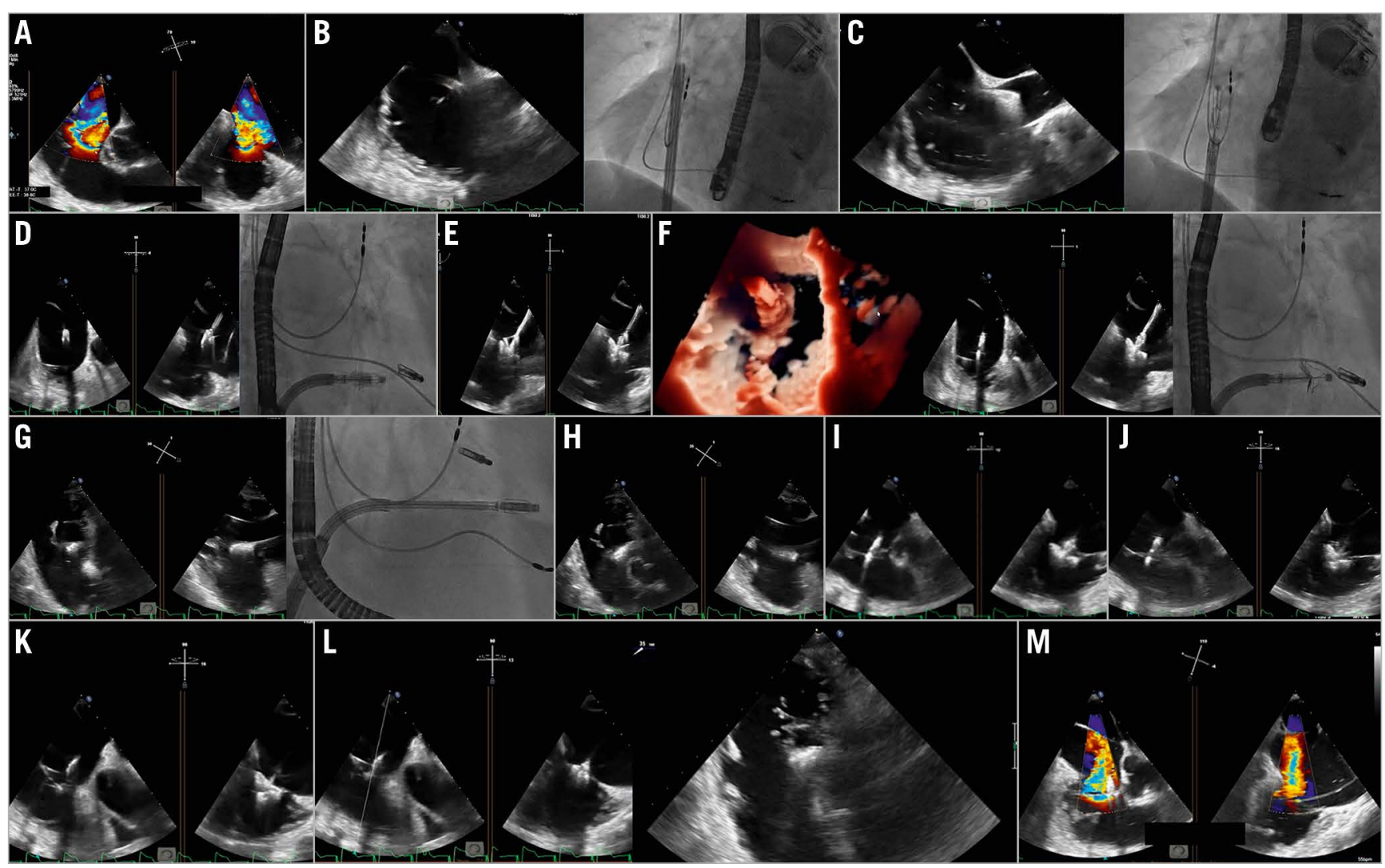

Figure 16. Tricuspid PASCAL procedure. A) Baseline evaluation. B) Guide sheath placement inside the RA. C) Implant system insertion. D) Trajectory. E) Clasp check. F) Implant orientation. G) Valve crossing. H) Confirmation of implant orientation. I) Implant retraction. J) Leaflet clasping. K) \& L) Assessment of leaflet insertion. M) Result evaluation after implant release. Courtesy of Dr Ralph Stephan Von Bardeleben, Department of Cardiology I, Heart Valve Center, Universitätsmedizin Mainz, Mainz, Germany. RA: right atrium 
a contrast-enhanced TOE should be performed in order to confirm the exact location of the shunt and PFO anatomy.

An ostium secundum represents the only type of ASD that can be closed percutaneously in the majority of cases. Anecdotal cases of percutaneous closure of other ASD types have been reported ${ }^{56}$. Percutaneous closure of an ASD is considered the first-choice treatment for ostium secundum $\mathrm{ASD}^{57}$. Exclusion criteria for percutaneous treatment $\left.\operatorname{are}^{54,58}: 1\right)$ stretched defect diameter greater than $38 \mathrm{~mm}$; 2) partial anomalous venous connection requiring surgical repair; and 3) absence or partial deficit $(<5 \mathrm{~mm})$ of rims with the exception of the aortic one.

\section{PROCEDURAL STEPS AND IMAGING GUIDANCE}

Percutaneous PFO closure usually involves a double disc device or a suture-mediated device and can be performed using fluoroscopy only. However, echographic guidance is recommended to monitor the procedure in order to increase its safety, efficacy and to assess the final result. On fluoroscopy, the procedure is normally followed in a shallow LAO cranial projection.

When a double disc device is used, the procedure steps are the same for both PFO and ASD closure as follows (Figure 17, Supplementary Table 10): 1) right venous femoral access; 2) crossing of the PFO/ASD with a multipurpose catheter; 3) positioning of the device delivery sheath across the IAS on a stiff wire (directed in the left upper pulmonary vein); 4) sequential opening of the left and the right atrial discs of the device. The correct position of the device is finally assessed. The aim is to check the two discs lying parallel to each other between the IAS, to systematically review the rims and edges of the device, to rule out interference with other structures. Moreover, colour-Doppler allows evaluation of the possible persistence of a left-to-right shunt at the edges of the device or within it, and finally, 5) stability manoeuvre and the final release.

In case of ASD closure, a sizing balloon is required. The balloon is inflated with the contrast medium until ASD occlusion (no shunt at colour-Doppler). ASD balloon-stretched diameters can be obtained on a simultaneous 2D biplane view. These correspond to the balloon waist that can be observed and measured either with echocardiography or fluoroscopy. Once sizing of the defect is performed, the size of the device is chosen with an oversizing of about $30 \%$.

Baseline and final contrast studies to assess the closure of the PFO are recommended.

When a suture-mediated device is used, a first suture is deployed on the septum secundum, then a suture on the septum primum, and finally the sutures are tightened together by deploying a small plastic knot and a final angiogram is performed. The $\mathrm{C}$-arm is positioned in a steep $\mathrm{LAO}\left(60^{\circ}\right)$ projection

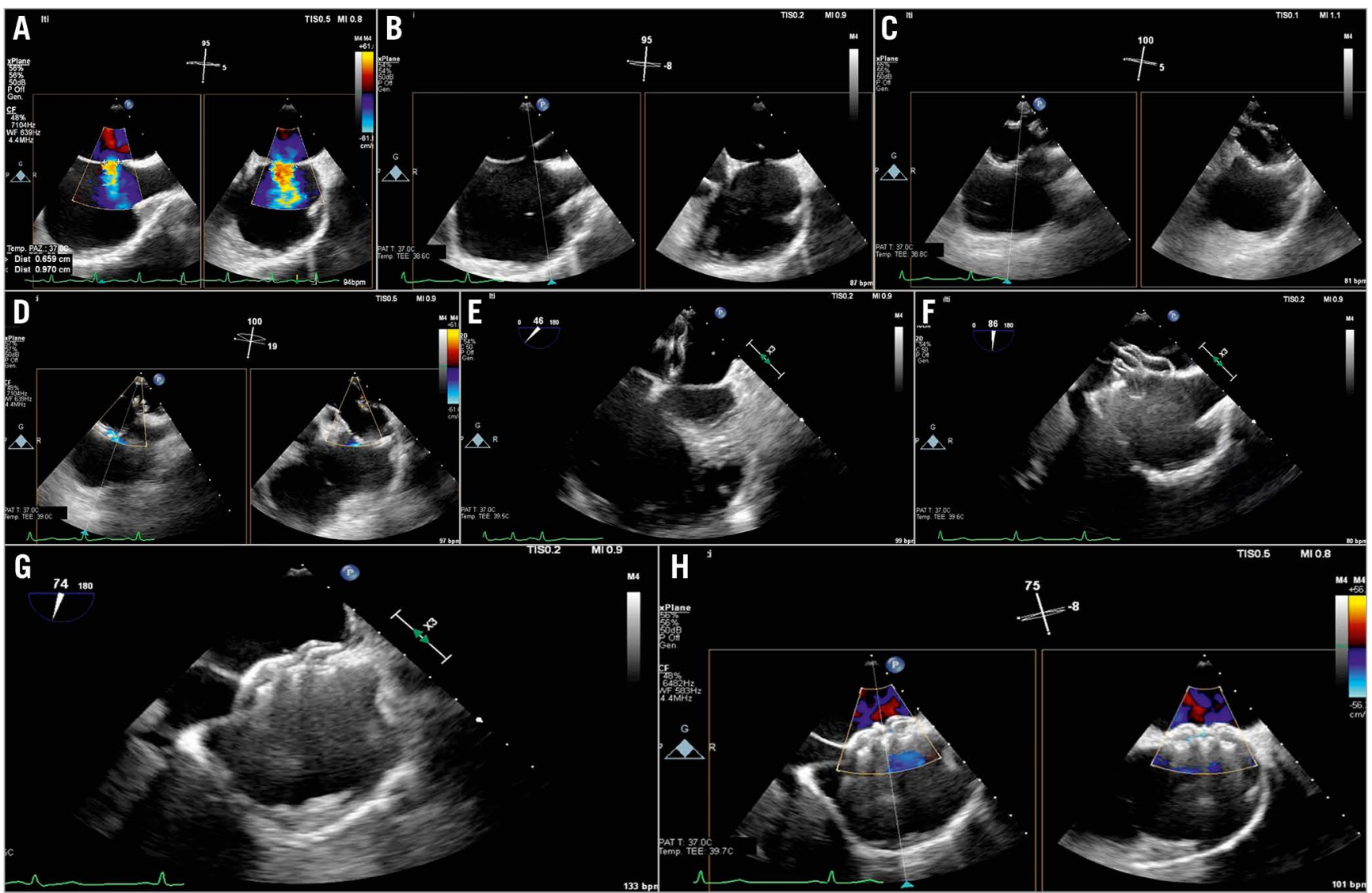

Figure 17. ASD closure procedure. A) Baseline evaluation and sizing of the defect. B) ASD crossing. C) \& D) Balloon sizing. E) Left disc opening. F) Right disc opening and push-and-pull test. G) Device release. H) Colour-Doppler shows absence of residual shunt. ASD: atrial septal defect 
and the X-ray tube should not be moved throughout the procedure, hence a vertebral body marks the exact position of the septum primum and secundum, the target of the sutures. During the procedure, TOE might follow the passage of the wires and of the catheters, monitor complications and the final result; however, the sutures and their deployment needles are not visible on echocardiography.

ICE is an excellent tool for intraprocedural guidance during percutaneous PFO closure.

The ICE catheter is introduced transfemorally in the right atrium. If a catheter with a linear probe is used, the transducer needs to be oriented towards the interatrial septum (by turning the catheter under fluoroscopic guidance).

Bidimensional imaging will visualise the IAS and its anatomical characteristics. By injecting ultrasonic contrast medium in the femoral or peripheral vein, the degree and characteristics of the right-to-left shunt can be assessed. Colour-Doppler imaging can confirm additional left-to-right shunts and assess the colour flow across the PFO. In case of balloon interrogation of the PFO, the sizing balloon can be easily visualised by ICE. In case of doubledisc devices, the ICE in the long axis atrial septal view is able to visualise all the steps of the procedure with the left atrial disc opening, its approximation towards the IAS and the right disc opening. The device can be assessed in two planes before the final release and colour Doppler can assess potential residual shunts (Figure 18).

\section{FOLLOW-UP}

TTE provides adequate images of the occluder device using the apical four-chamber view and subxiphoid acoustic windows. The degree of residual shunt can be easily quantified by the echographic contrast medium injection.

\section{PERCUTANEOUS CLOSURE OF PARAVALVULAR LEAKS}

PVL is a complication after surgical or transcatheter valve replacement. About $1-5 \%$ of PVLs can lead to serious consequences, including congestive heart failure and haemolytic anaemia. Traditionally, surgical re-intervention has been considered the treatment of choice for symptomatic patients with PVLs. However, it is associated with a high risk of morbidity and mortality, and the percutaneous option has emerged as a less invasive alternative.

\section{INDICATIONS FOR PVL CLOSURE}

In general, there are two indications for the closure of a PVL ${ }^{59}$ :

1. Patients with significant regurgitation due to the PVL and symptoms of congestive heart failure.

2. Patients with significant regurgitation due to the PVL and haemolysis.

Important contraindications to PVL closure include presence of active local or systemic infection, active ischaemia, mechanical instability of the prosthetic valve, intracardiac thrombus, and patients with a life expectancy due to comorbidities that is less than six months.

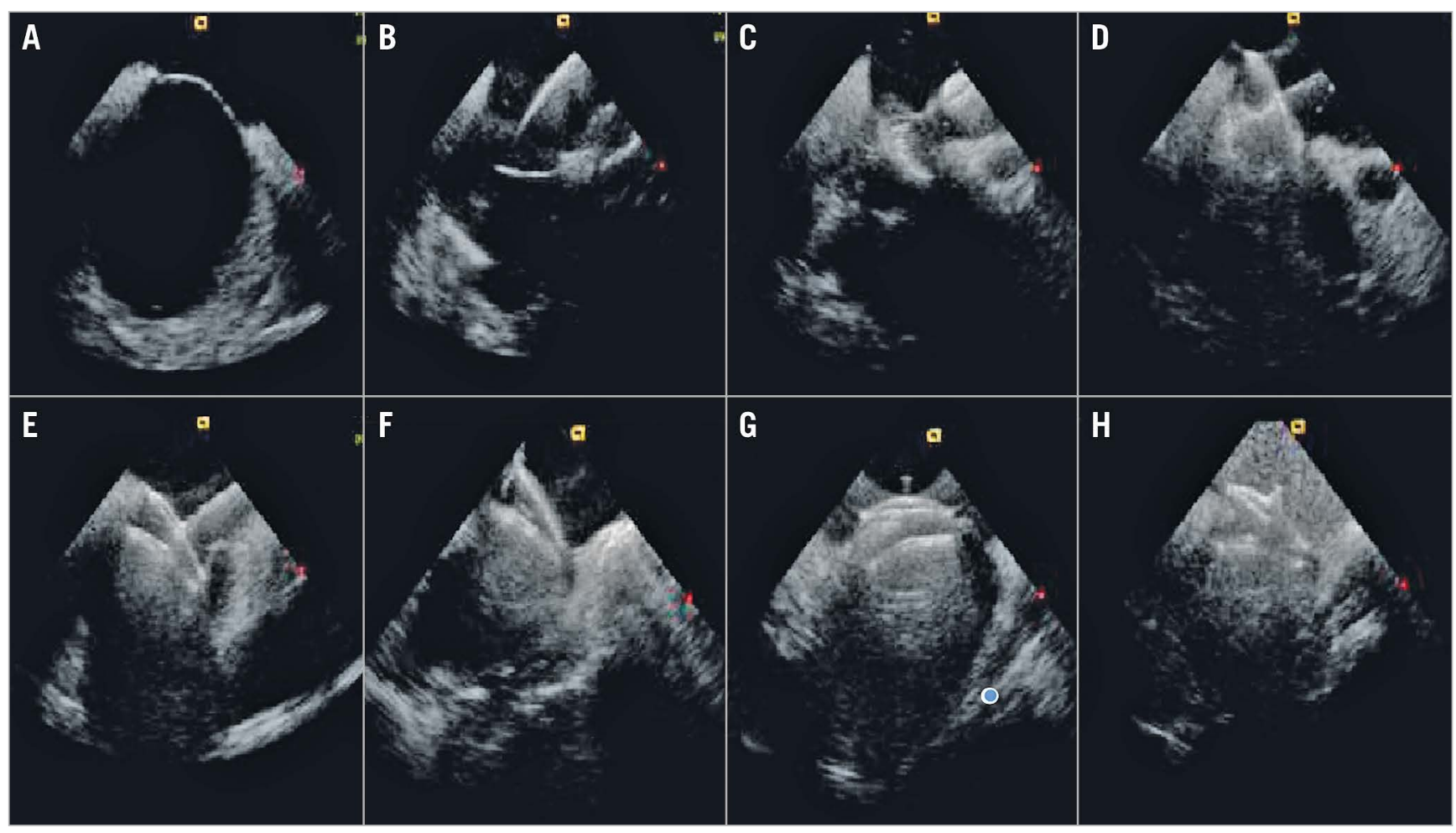

Figure 18. ICE guidance of a double disc device PFO closure. A) Long-axis atrial septal view at baseline. B) Left atrial disc opening. C) Approximation towards the IAS. D) The right disc opening. The device can be assessed in two planes ( $E \& F$ ) before the final release. After the final release $(G)$, the bubble test should be repeated in order to assess the immediate result $(H)$. IAS: interatrial septum; ICE: intracardiac echocardiography PFO: patent foramen ovale 


\section{PREPROCEDURAL EVALUATION AND PREPROCEDURAL PLANNING}

TOE, particularly 3D TOE, is the imaging modality of choice in percutaneous PVL closure ${ }^{60}$. It plays an essential role in evaluating the defect, guiding the procedure, monitoring complications and assessing the results. Specifically, mitral PVL closure is a highly echo-dependent intervention.

An exhaustive evaluation of PVL anatomy is essential for the success of the procedure. Real-time 3D TOE imaging is especially useful to this end, particularly in mitral PVL. However, paravalvular defects should be confirmed with colour Doppler to avoid confusion with areas of echo drop-out due to low spatial resolution (Figure 19).

Furthermore, during preprocedural TOE, it is important to evaluate the presence of pericardial effusion and intracardiac thrombus and the transprosthetic gradient. In the presence of intracardiac thrombus, the procedure must be postponed. Pulmonary vein inflow for mitral leaks or descending aorta flow for aortic leaks should also be documented. Finally, the relation with adjoining structures (coronary arteries, calcium...) should be examined.
The shape of the cross-sectional area of the vena contracta (oval, irregular...), the vena contracta diameters, and the channel length determine the choice and size of occluding devices. Moreover, a surgical suture crossing the defect can impact on the choice of the devices and should be evaluated.

CT can provide additive information. Cardiac CT angiography can easily define location, size, shape, and trajectory of a PVL by MPR. Moreover, CT analysis allows preprocedural determination of the optimal fluoroscopic plane to be used during the procedure.

\section{TOE GUIDANCE FOR PVL CLOSURE}

The procedure is performed under fluoroscopic and TOE guidance (Figure 20A-Figure 20D, Supplementary Table 11).

During the procedure, only a target-oriented TOE is performed to confirm size, shape and location of the leak. TOE is used to guide the TSP, to help the crossing of the guidewire and catheter through the defect, to ensure an adequate positioning of the device over the defect, to evaluate prosthetic valve function, and to identify complications. To evaluate the results, the absence or

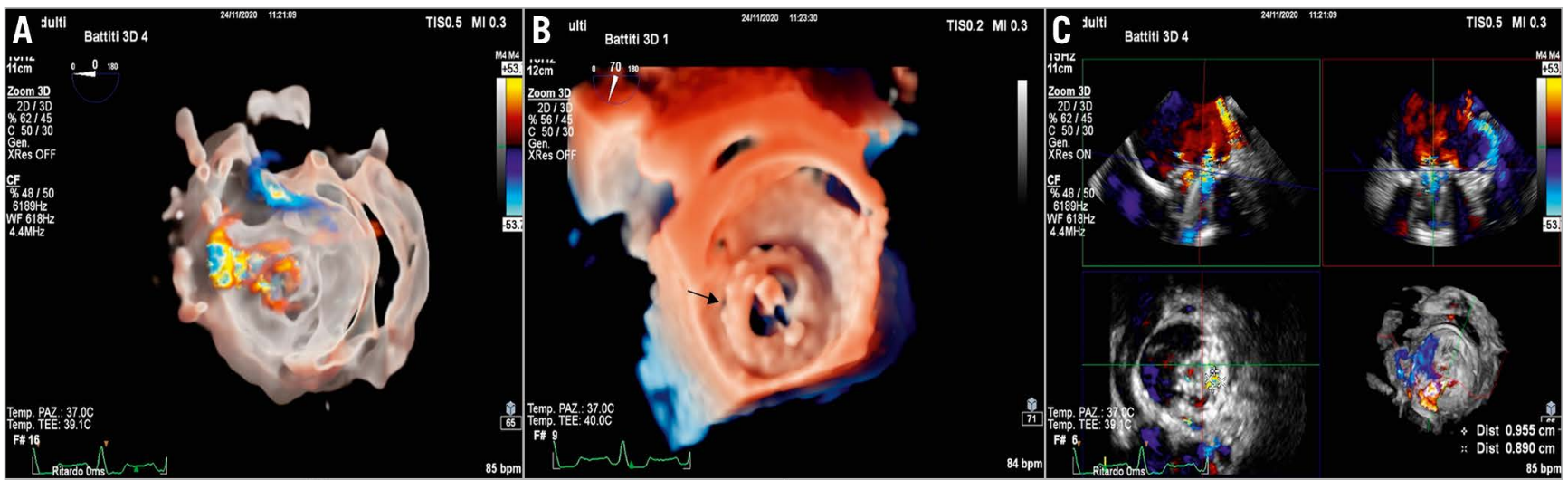

D

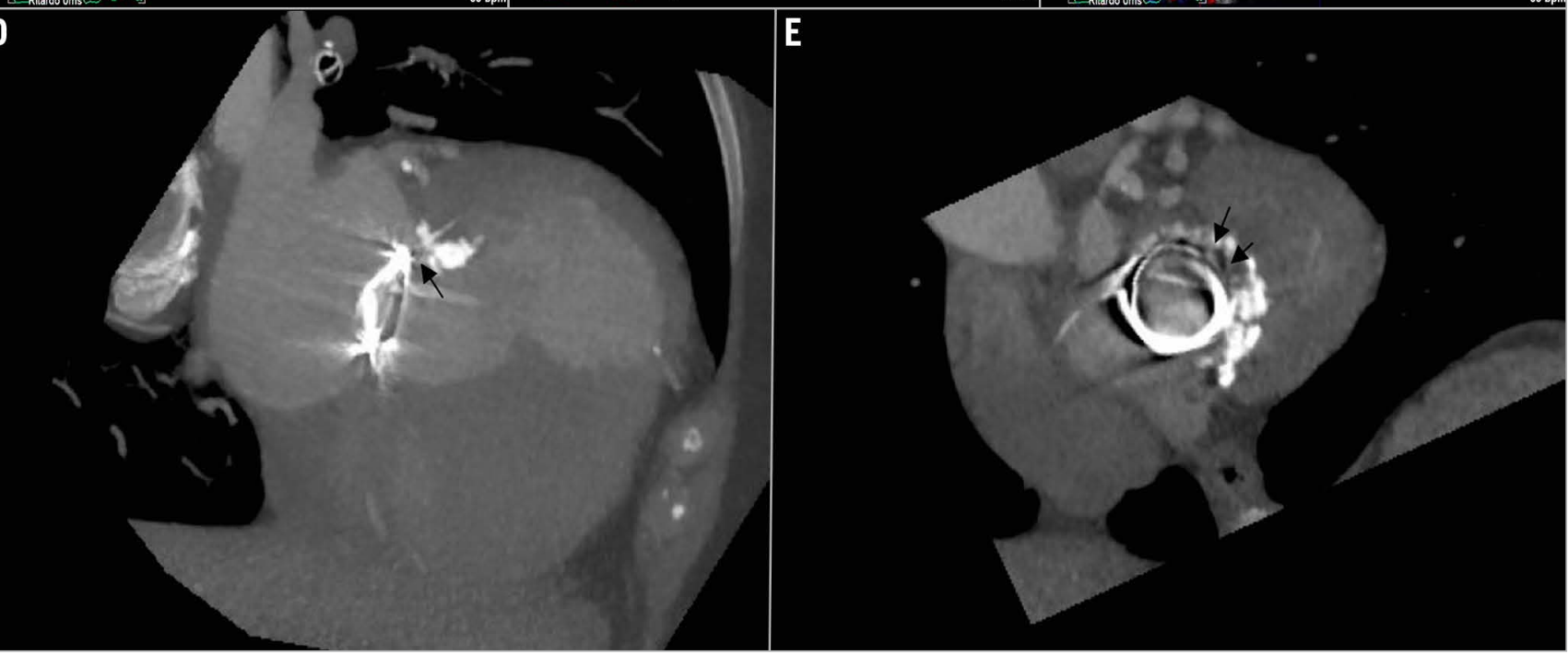

Figure 19. Leak evaluation and preprocedural planning. $A \&$ \&) Localisation of mitral PVL. A) 3D colour-Doppler (transparency rendering).

B) En face view of mitral valve prosthesis (3D true view rendering). C) Leak sizing by 3D MPR. D \& E) Computed tomography (CT).

D) Coronal view. E) Axial view of the prosthesis. CT evaluation is helpful particularly for sizing of the PVL and for deriving the working fluoroscopic projection. MPR: multiplanar reconstruction; PVL: paravalvular leak 

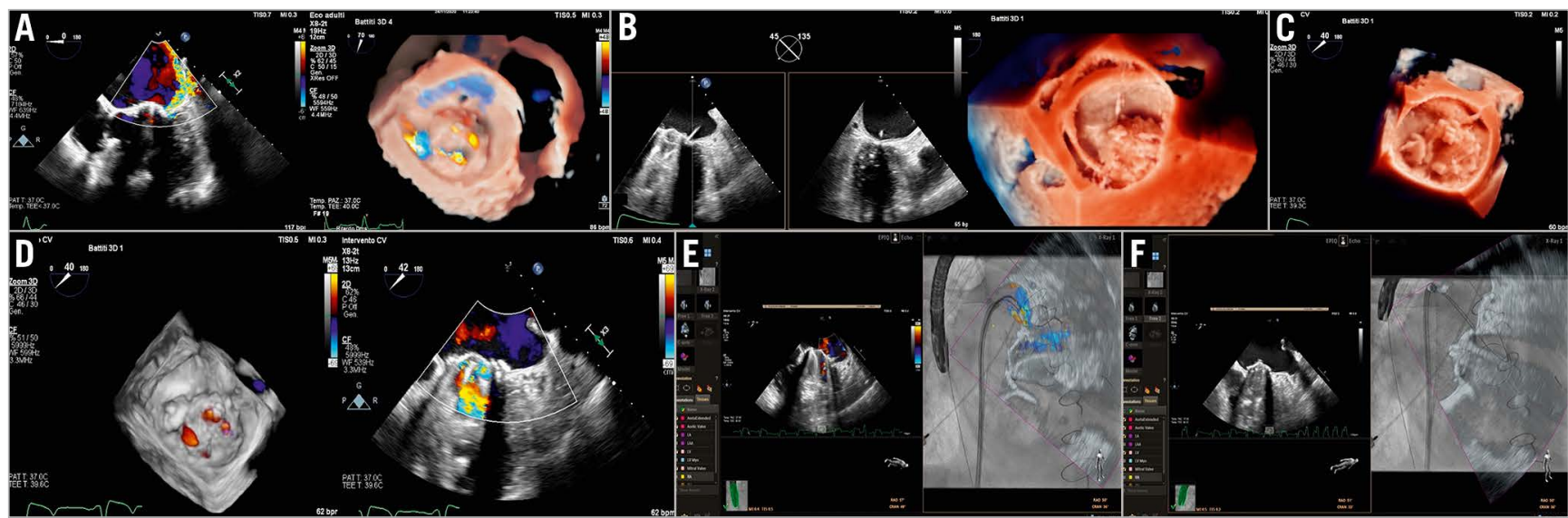

Figure 20. Mitral PVL closure procedure. A) Baseline evaluation. B) PVL crossing by hydrophilic guidewire. C) PVL crossing by hydrophilic guidewire. C) Device deployment. D) Final result. E\& F) Fusion imaging. E) Colour-Doppler superimposed to fluoroscopy. The colour jet is used as a marker. F) 2D imaging superimposed to fluoroscopy showing the PVL crossing. PVL: paravalvular leak

reduction of colour-Doppler flow is the first and simplest sign of success. The 3D cross-sectional area of the vena contracta before and after the procedure can be compared, as well as prosthesis gradient and pulmonary vein (mitral leak) or descending aorta flow (aortic leak) in similar haemodynamic conditions.

In some patients with aortic PVL and contraindications to TOE, a procedure monitored solely by TTE could be carried out, but a previous $\mathrm{CT}$ is mandatory in this case.

Echo-fluoroscopic fusion imaging has simplified the percutaneous procedures of transcatheter PVL closure, particularly in cases of radiolucent prosthetic valves ${ }^{61}$. By superimposing 2D, colour Doppler and 3D modalities on fluoroscopy, the fusion may help to (Figure 20E, Figure 20F):

- Carry out the TSP

- Identify the site of the leak on the fluoroscopic projection

- Engage the leak

- Deploy the device

- Evaluate the interference with prosthesis

\section{RISK OF RADIATION EXPOSURE}

The interventional imager can be subjected to high levels of radiation exposure due to their proximity to the X-ray source. Thus, a number of simple measures, such as the use of a protective lead coat, portable lead shielding, radiation reducing gloves, and distancing from the X-ray source, must be taken to minimise exposure and the associated risks ${ }^{62}$. In addition, the imager should be monitored for radiation doses during procedures and a record of the cumulative dose maintained. Using a remote controlled robotic arm for real-time echocardiographic monitoring during procedures could be a future solution.

\section{GREY AREAS AND FUTURE DIRECTIONS}

Despite an increased demand for physicians with specific technical skills and competencies in SHD imaging, there is no standardised core curriculum for SHD interventional imagers so far ${ }^{62}$.
The presence of metallic artefacts, as well as occasional difficulties in discerning tissue from devices/catheters, still represent a challenge for the imager. The development of specific tools, able to identify the different components by different colour codes, could facilitate the work of the team.

Accurate evaluation of the procedural result after device implantation is another open challenge. The presence of multiple jets, eccentricity, etc., make the use of the standard quantification methods unreliable. Thus, new software enabling semi-automated $3 \mathrm{D}$ flow quantification could be more accurate than conventional methods ${ }^{63}$.

\section{Conclusions}

Imaging plays a central role for clinical decision making in SHD: before the procedure, to decide appropriateness and feasibility, as well as for intraprocedural guidance and post-procedural followup. The continuous expansion of device availability benefits from the improvements in the field of imaging. Consequently, interventional imaging as a subspecialty is likely to become more and more important with the development of a newer type of specialist, the "SHD Interventional Imager".

\section{Conflict of interest statement}

The authors have no conflicts of interest to declare.

\section{References}

1. Rubio-Alvarez V, Limon R, Soni J. Valvulotomias intracardiacas por medio de un cateter [Intracardiac valvulotomy by means of a catheter]. [Article in Undertermined language]. Arch Inst Cardiol Mex. 1953;23:183-92.

2. Vignola PA, Swaye PS, Gosselin AJ. Safe transthoracic left ventricular puncture performed with echocardiographic guidance. Cathet Cardiovasc Diagn. 1980;6: 317-24.

3. Hellenbrand WE, Fahey JT, McGowan FX, Weltin GG, Kleinman CS. Transesophageal echocardiographic guidance of transcatheter closure of atrial septal defect. Am J Cardiol. 1990;66:207-13.

4. Ballal RS, Mahan EF 3rd, Nanda NC, Dean LS. Utility of transesophageal echocardiography in interatrial septal puncture during percutaneous mitral balloon commissurotomy. Am J Cardiol. 1990;66:230-2. 
5. Daoud EG, Kalbfletsch SJ, Hummel JD. Intracardiac echocardiography to guide transseptal left heart catheterization for radiofrequency catheter ablation. J Cardiovasc Electrophysiol. 1999;10:358-63.

6. Nijenhuis VJ, Alipour A, Wunderlich NC, Rensing BJWM, Gijsbers G, Ten Berg JM, Suttorp MJ, Boersma LVA, van der Heyden JAS, Swaans MJ. Feasibility of multiplane microtransoesophageal echocardiographic guidance in structural heart disease transcatheter interventions in adults. Neth Heart J. 2017;25:669-74.

7. Corti R, Biaggi P, Gaemperli O, Bühler I, Felix C, Bettex D, Kretschmar O, Falk V, Grünenfelder J. Integrated $\mathrm{x}$-ray and echocardiography imaging for structural heart interventions. EuroIntervention. 2013;9:863-9.

8. Krishnaswamy A, Tuzcu EM, Kapadia SR. Integration of MDCT and fluoroscopy using C-arm computed tomography to guide structural cardiac interventions in the cardiac catheterization laboratory. Catheter Cardiovasc Interv. 2015;85:139-47.

9. Bruckheimer E, Rotschild C, Dagan T, Amir G, Kaufman A, Gelman S, Birk E. Computer-generated real-time digital holography: first time use in clinical medical imaging. Eur Heart J Cardiovasc Imaging. 2016;17:845-9.

10. Vahanian A, Brochet E. Transseptal puncture for structural heart intervention: an old technique with new indications. Heart. 2017;103:1830-7.

11. Agricola E. Interventional echocardiography. Turin, Italy: Edizioni Minerva Medica; 2020 .

12. Squara F, Bres M, Baudouy D, Schouver ED, Moceri P, Ferrari E. Transesophageal echocardiography for the assessment of left atrial appendage thrombus: Study of the additional value of systematic real time 3D imaging after regular $2 \mathrm{D}$ evaluation. Echocardiography. 2018;35:474-80

13. Spagnolo P, Giglio M, Di Marco D, Cannaò PM, Agricola E, Della Bella PE, Monti CB, Sardanelli F. Diagnosis of left atrial appendage thrombus in patients with atrial fibrillation: delayed contrast-enhanced cardiac CT. Eur Radiol. 2021;31: 1236-44.

14. Freitas-Ferraz AB, Bernier M, O'Connor K, Beaudoin J, Champagne J, Paradis JM, O'Hara G, Muntané-Carol G, Alperi A, Faroux L, Junquera L, Rodés-Cabau J. Safety and effects of volume loading during transesophageal echocardiography in the preprocedural work-up for left atrial appendage closure. Cardiovasc Ultrasound. 2021; 19:3

15. Tzikas A, Holmes DR Jr, Gafoor S, Ruiz CE, Blomström-Lundqvist C, Diener HC, Cappato R, Kar S, Lee RJ, Byrne RA, Ibrahim R, Lakkireddy D, Soliman OI, Nabauer M, Schneider S, Brachmann J, Saver JL, Tiemann K, Sievert H, Camm AJ, Lewalter T. Percutaneous left atrial appendage occlusion: the Munich consensus document on definitions, endpoints, and data collection requirements for clinical studies. Europace. 2017;19:4-15.

16. Balzer J, Zeus T, Veulemans V, Kelm M. Hybrid Imaging in the Catheter Laboratory: Real-time Fusion of Echocardiography and Fluoroscopy During Percutaneous Structural Heart Disease Interventions. Interv Cardiol. 2016;11:59-64.

17. Jungen C, Zeus T, Balzer J, Eickholt C, Petersen M, Kehmeier E, Veulemans V, Kelm M, Willems S, Meyer C. Left Atrial Appendage Closure Guided by Integrated Echocardiography and Fluoroscopy Imaging Reduces Radiation Exposure. PLoS One. 2015;10:e0140386.

18. Berti S, Paradossi U, Meucci F, Trianni G, Tzikas A, Rezzaghi M, Stolkova M, Palmieri C, Mori F, Santoro G. Periprocedural intracardiac echocardiography for left atrial appendage closure: a dual-center experience. JACC Cardiovasc Interv. 2014;7: 1036-44.

19. Aguirre D, Pincetti C, Perez L, Deck C, Alfaro M, Vergara MJ, Maluenda G. Single trans-septal access technique for left atrial intracardiac echocardiography to guide left atrial appendage closure. Catheter Cardiovasc Interv. 2018;91:356-61.

20. Masson JB, Kouz R, Riahi M, Nguyen Thanh HK, Potvin J, Naim C, Salem R, Raymond JM. Transcatheter Left Atrial Appendage Closure Using Intracardiac Echocardiographic Guidance From the Left Atrium. Can J Cardiol. 2015;31:1497.

21. Bertrand PB, Grieten L, De Meester P, Verbrugge FH, Mullens W, Verhaert D, Rivero-Ayerza M, Budts W, Vandervoort PM. Etiology and relevance of the figure-ofeight artifact on echocardiography after percutaneous left atrial appendage closure with the Amplatzer Cardiac Plug. J Am Soc Echocardiogr. 2014;27:323-8.

22. Saw J, Fahmy P, DeJong P, Lempereur M, Spencer R, Tsang M, Gin K, Jue J, Mayo J, McLaughlin P, Nicolaou S. Cardiac CT angiography for device surveillance after endovascular left atrial appendage closure. Eur Heart J Cardiovasc Imaging. 2015; 16:1198-206

23. Lim YM, Kim JS, Kim TH, Uhm JS, Shim CY, Joung B, Hong GR, Lee MH, Jang YS, Pak HN. Delayed left atrial appendage contrast filling in computed tomograms after percutaneous left atrial appendage occlusion. J Cardiol. 2017;70:571-7.

24. Del Forno B, De Bonis M, Agricola E, Melillo F, Schiavi D, Castiglioni A, Montorfano M, Alfieri O. Mitral valve regurgitation: a disease with a wide spectrum of therapeutic options. Nat Rev Cardiol. 2020;17:807-27.

25. Herrmann HC, Kar S, Siegel R, Fail P, Loghin C, Lim S, Hahn R, Rogers JH, Bommer WJ, Wang A, Berke A, Lerakis S, Kramer P, Wong SC, Foster E, Glower D,
Feldman T; EVEREST Investigators. Effect of percutaneous mitral repair with the MitraClip device on mitral valve area and gradient. EuroIntervention. 2009;4:437-42. 26. Zoghbi WA, Asch FM, Bruce C, Gillam LD, Grayburn PA, Hahn RT, Inglessis I, Islam AM, Lerakis S, Little SH, Siegel RJ, Skubas N, Slesnick TC, Stewart WJ, Thavendiranathan P, Weissman NJ, Yasukochi S, Zimmerman KG. Guidelines for the Evaluation of Valvular Regurgitation After Percutaneous Valve Repair or Replacement: A Report from the American Society of Echocardiography Developed in Collaboration with the Society for Cardiovascular Angiography and Interventions, Japanese Society of Echocardiography, and Society for Cardiovascular Magnetic Resonance. J Am Soc Echocardiogr. 2019;32:431-75.

27. Seeger J, Müller P, Gonska B, Scharnbeck D, Markovic S, Walcher D, Rottbauer W, Wöhrle J. Percutaneous Mitral Valve Repair With the MitraClip in Primary Compared With Secondary Mitral Valve Regurgitation Using the Mitral Valve Academic Research Consortium Criteria. J Invasive Cardiol. 2017;29:145-50.

28. Smith T, McGinty P, Bommer W, Low RI, Lim S, Fail P, Rogers JH. Prevalence and echocardiographic features of iatrogenic atrial septal defect after catheter-based mitral valve repair with the MitraClip system. Catheter Cardiovasc Interv. 2012;80:678-85. 29. Wunderlich NC, Beigel R, Ho SY, Nietlispach F, Cheng R, Agricola E, Siegel RJ. Imaging for Mitral Interventions: Methods and Efficacy. JACC Cardiovasc Imaging. 2018;11:872-901.

30. Melillo F, Ancona F, Romano V, Ingallina G, Capogrosso C, Stella S, Montorfano M, Agricola E. Imaging di fusione nell'interventistica strutturale [Fusion imaging in structural heart interventions]. [Article in Italian]. G Ital Cardiol (Rome). 2020;21: $34 \mathrm{~S}-41 \mathrm{~S}$.

31. Melillo F, Fisicaro A, Stella S, Ancona F, Capogrosso C, Ingallina G, Maccagni D, Romano V, Ruggeri S, Godino C, Latib A, Montorfano M, Colombo A, Agricola E. Systematic Fluoroscopic-Echocardiographic Fusion Imaging Protocol for Transcatheter Edge-to-Edge Mitral Valve Repair Intraprocedural Monitoring. J Am Soc Echocardiogr. 2021;34:604-13.

32. Faletra FF, Pozzoli A, Agricola E, Guidotti A, Biasco L, Leo LA, Taramasso M, Pasotti E, Kuwata S, Moccetti M, Tanner FC, Pedrazzini G, Nietlispach F, Moccetti T, Zuber M, Maisano F. Echocardiographic-fluoroscopic fusion imaging for transcatheter mitral valve repair guidance. Eur Heart J Cardiovasc Imaging. 2018;19:715-26.

33. Singh JP, Evans JC, Levy D, Larson MG, Freed LA, Fuller DL, Lehman B, Benjamin EJ. Prevalence and clinical determinants of mitral, tricuspid, and aortic regurgitation (the Framingham Heart Study). Am J Cardiol. 1999;83:897-902.

34. Baumgartner H, Falk V, Bax JJ, De Bonis M, Hamm C, Holm PJ, Iung B, Lancellotti P, Lansac E, Muñoz DR, Rosenhek R, Sjögren J, Tornos Mas P, Vahanian A, Walther T, Wendler O, Windecker S, Zamorano JL; ESC Scientific Document Group. $2017 \mathrm{ESC} / \mathrm{EACTS}$ Guidelines for the management of valvular heart disease. Eur Heart J. 2017;38:2739-91.

35. LaPar DJ, Likosky DS, Zhang M, Theurer P, Fonner CE, Kern JA, Bolling SF, Drake DH, Speir AM, Rich JB, Kron IL, Prager RL, Ailawadi G; Investigators for the Virginia Cardiac Surgery Quality Initiative and the Michigan Society of Thoracic and Cardiovascular Surgeons. Development of a Risk Prediction Model and Clinical Risk Score for Isolated Tricuspid Valve Surgery. Ann Thorac Surg. 2018;106:129-36.

36. Lang RM, Badano LP, Mor-Avi V, Afilalo J, Armstrong A, Ernande L, Flachskampf FA, Foster E, Goldstein SA, Kuznetsova T, Lancellotti P, Muraru D, Picard MH, Rietzschel ER, Rudski L, Spencer KT, Tsang W, Voigt JU. Recommendations for cardiac chamber quantification by echocardiography in adults: an update from the American Society of Echocardiography and the European Association of Cardiovascular Imaging. J Am Soc Echocardiogr. 2015;28:1-39.

37. Hahn RT, Zamorano JL. The need for a new tricuspid regurgitation grading scheme. Eur Heart J Cardiovasc Imaging. 2017;18:1342-3.

38. Hahn RT, Abraham T, Adams MS, Bruce CJ, Glas KE, Lang RM, Reeves ST, Shanewise JS, Siu SC, Stewart W, Picard MH. Guidelines for performing a comprehensive transesophageal echocardiographic examination: recommendations from the American Society of Echocardiography and the Society of Cardiovascular Anesthesiologists. J Am Soc Echocardiogr. 2013;26:921-64.

39. Pardo Sanz A, Sánchez Recalde Á, Salido Tahoces L, Fernández-Golfín Lobán C, Zamorano Gómez JL. MSCT-fluoroscopy fusion imaging for guidance in percutaneous bicaval valve implantation for transcatheter treatment of tricuspid regurgitation. Eur Hear J Cardiovasc Imaging. 2020;21:1303.

40. Agricola E, Ancona F, Stella S, Rosa I, Marini C, Spartera M, Denti P, Margonato A, Hahn RT, Alfieri O, Colombo A, Latib A. Use of Echocardiography for Guiding Percutaneous Tricuspid Valve Procedures. JACC Cardiovasc Imaging. 2017;10: $1194-8$

41. Taramasso M, Alessandrini H, Latib A, Asami M, Attinger-Toller A, Biasco L, Braun D, Brochet E, Connelly KA, Denti P, Deuschl F, Englmeier A, Fam N, Frerker C, Hausleiter J, Himbert D, Ho EC, Juliard JM, Kaple R, Kreidel F, Kuck KH, Ancona M, Lauten A, Lurz P, Mehr M, Nazif T, Nickening G, Pedrazzini G, Pozzoli A, Praz F, Puri R, Rodés-Cabau J, Schäfer U, Schofer J, Sievert H, Sievert K, Tang GHL, Tanner FC, Vahanian A, Webb JG, Windecker S, Yzeiray E, Zuber M, Maisano F, 
Leon MB, Hahn RT. Outcomes After Current Transcatheter Tricuspid Valve Intervention; Mid-Term Results From the International TriValve Registry. JACC Cardiovasc Interv. 2019;12:155-65.

42. Lurz P, Orban M, Besler C, Braun D, Schlotter F, Noack T, Desch S, Karam N, Kresoja KP, Hagl C, Borger M, Nabauer M, Massberg S, Thiele H, Hausleiter J, Rommel KP. Clinical characteristics, diagnosis, and risk stratification of pulmonary hypertension in severe tricuspid regurgitation and implications for transcatheter tricuspid valve repair. Eur Heart J. 2020;41:2785-95.

43. Stocker TJ, Hertell H, Orban M, Braun D, Rommel KP, Ruf T, Ong G, Nabauer M, Deseive S, Fam N, von Bardeleben RS, Thiele H, Massberg S, Lurz P, Hausleiter J. Cardiopulmonary Hemodynamic Profile Predicts Mortality After Transcatheter Tricuspid Valve Repair in Chronic Heart Failure. JACC Cardiovasc Interv. 2021;14 29-38.

44. Schueler R, Hammerstingl C, Werner N, Nickenig G. Interventional Direct Annuloplasty for Functional Tricuspid Regurgitation. JACC Cardiovasc Interv. 2017; 10:415-6.

45. Latib A, Agricola E, Pozzoli A, Denti P, Taramasso M, Spagnolo P, Juliard JM, Brochet E, Ou P, Enriquez-Sarano M, Grigioni F, Alfieri O, Vahanian A, Colombo A, Maisano F. First-in-Man Implantation of a Tricuspid Annular Remodeling Device for Functional Tricuspid Regurgitation. JACC Cardiovasc Interv. 2015;8:e211-4.

46. Agricola E, Ancona F, Baldetti L, Stella S, Capogrosso C, Margonato A, Colombo A, Castiglioni A, Fisicaro A, Montorfano M, Alfieri O, Latib A. Nuove possibilità terapeutiche nel trattamento dell'insufficienza tricuspidale [New therapeutic options for the treatment of tricuspid regurgitation]. G Ital Cardiol (Rome). 2019; 20:85-96.

47. Agricola E, Asmarats L, Maisano F, Cavalcante JL, Liu S, Milla F, Meduri C, Rodés-Cabau J, Vannan M, Pibarot P. Imaging for Tricuspid Valve Repair and Replacement. JACC Cardiovasc Imaging. 2021;14:61-111.

48. Clark EB. Pathogenetic mechanisms of congenital cardiovascular malformations revisited. Semin Perinatol. 1996;20:465-72.

49. Lechat P, Mas JL, Lascault G, Loron P, Theard M, Klimczac M, Drobinski G, Thomas D, Grosgogeat Y. Prevalence of patent foramen ovale in patients with stroke. N Engl J Med. 1988;318:1148-52.

50. Webster MW, Chancellor AM, Smith HJ, Swift DL, Sharpe DN, Bass NM, Glasgow GL. Patent foramen ovale in young stroke patients. Lancet. 1988;2:11-2.

51. Handke M, Harloff A, Olschewski M, Hetzel A, Geibel A. Patent foramen ovale and cryptogenic stroke in older patients. $N$ Engl J Med. 2007;357:2262-8.

52. Hildick-Smith D, Williams TM. Patent Foramen Ovale and Migraine Headache. Interv Cardiol Clin. 2017;6:539-45.

53. Mojadidi MK, Ruiz JC, Chertoff J, Zaman MO, Elgendy IY, Mahmoud AN, Al-Ani M, Elgendy AY, Patel NK, Shantha G, Tobis JM, Meier B. Patent Foramen Ovale and Hypoxemia. Cardiol Rev. 2019;27:34-40.

54. Silvestry FE, Cohen MS, Armsby LB, Burkule NJ, Fleishman CE, Hijazi ZM, Lang RM, Rome JJ, Wang Y; American Society of Echocardiography, Society for Cardiac Angiography and Interventions. Guidelines for the Echocardiographic Assessment of Atrial Septal Defect and Patent Foramen Ovale: From the American Society of Echocardiography and Society for Cardiac Angiography and Interventions. $J$ Am Soc Echocardiogr. 2015;28:910-58.

55. Pristipino C, Sievert H, D'Ascenzo F, Mas JL, Meier B, Scacciatella P, HildickSmith D, Gaita F, Toni D, Kyrle P, Thomson J, Derumeaux G, Onorato E, Sibbing D, Germonpré P, Berti S, Chessa M, Bedogni F, Dudek D, Hornung M, Zamorano J; European Association of Percutaneous Cardiovascular Interventions (EAPCI), European Stroke Organisation (ESO), European Heart Rhythm Association (EHRA), European Association for Cardiovascular Imaging (EACVI), Association for European Paediatric and Congenital Cardiology (AEPC), ESC Working group on GUCH, ESC Working group on Thrombosis, European Haematological Society (EHA). European position paper on the management of patients with patent foramen ovale. General approach and left circulation thromboembolism. EuroIntervention. 2019;14: 1389-402.

56. Batteux C, Meliani A, Brenot P, Hascoet S. Multimodality fusion imaging to guide percutaneous sinus venosus atrial septal defect closure. Eur Heart J. 2020;41:4444-5.
57. Baumgartner H, De Backer J, Babu-Narayan SV, Budts W, Chessa M, Diller GP, Lung B, Kluin J, Lang IM, Meijboom F, Moons P, Mulder BJM, Oechslin E, RoosHesselink JW, Schwerzmann M, Sondergaard L, Zeppenfeld K; ESC Scientific Document Group. 2020 ESC Guidelines for the management of adult congenital heart disease. Eur Heart J. 2021;42:563-645.

58. Butera G, Carminati M, Chessa M, Youssef R, Drago M, Giamberti A, Pomè G, Bossone E, Frigiola A. Percutaneous versus surgical closure of secundum atrial septal defect: comparison of early results and complications. Am Heart J. 2006;151:228-34.

59. Gafoor S, Franke J, Bertog S, Lam S, Vaskelyte L, Hofmann I, Sievert H, Matic P A Quick Guide to Paravalvular Leak Closure. Interv Cardiol Rev. 2015;10:112-7.

60. Hascoet S, Smolka G, Bagate F, Guihaire J, Potier A, Hadeed K, Lavie-Badie Y, Bouvaist H, Dauphin C, Bauer F, Nejjari M, Pillière R, Brochet E, Mangin L, Bonnet G, Ciobotaru V, Leurent G, Hammoudi N, Aminian A, Karsenty C, Spaulding C, Armero S, Collet F, Champagnac D, Ternacle J, Kloeckner M, Gerardin B, Isorni MA Multimodality imaging guidance for percutaneous paravalvular leak closure: Insights from the multi-centre FFPP register. Arch Cardiovasc Dis. 2018;111:421-31.

61. Beneduce A, Ancona F, Ancona MB, Romano V, Stella S, Capogrosso C, Montorfano M, Agricola E. Multimodality Imaging for Transcatheter Paravalvula Leak Closure in Radiolucent Mitral Bioprosthesis. Circ Cardiovasc Imaging. 2019;12:e09285

62. Agricola E, Ancona F, Brochet E, Donal E, Dweck M, Faletra F, Lancellotti P, Mahmoud-Elsayed H, Marsan NA, Maurovich-Hovart P, Monaghan M, Ribeiro J, Sade LE, Swaans M, Von Bardeleben RS, Wunderlich N, Zamorano JL, Popescu BA, Cosyns B, Edvardsen T; Reviewers: This document was reviewed by members of the 2018-2020 EACVI Scientific Documents Committee. The structural heart disease interventional imager rationale, skills and training: a position paper of the European Association of Cardiovascular Imaging. Eur Heart J Cardiovasc Imaging. 2021;22: 471-9.

63. Militaru S, Bonnefous O, Hami K, Langet H, Houard L, Allaire S, Pouleur A-C Dianis S, This A, Beauloye C, Vancraeynest D, Pasquet A, Vanoverschelde JL, Gerber BL. Validation of Semiautomated Quantification of Mitral Valve Regurgitation by Three-Dimensional Color Doppler Transesophageal Echocardiography. J Am Soc Echocardiogr. 2020;33:342-54

\section{Supplementary data}

Supplementary Table 1. Transseptal puncture.

Supplementary Table 2. LAA closure procedure.

Supplementary Table 3. Suitability for transcatheter leaflet approach repair.

Supplementary Table 4. Leaflet approach procedure.

Supplementary Table 5. Echocardiographic and haemodynamic parameters for grading MR severity leaflet repair.

Supplementary Table 6. Cardioband procedure.

Supplementary Table 7. Echocardiographic imaging of the tricuspid valve.

Supplementary Table 8. Procedural steps of direct annuloplasty of the TV.

Supplementary Table 9. Tricuspid leaflet approach.

Supplementary Table 10. PFO/ASD closure.

Supplementary Table 11. Procedural steps of mitral PVL closure

The supplementary data are published online at:

https://eurointervention.pcronline.com/

doi/10.4244/EIJ-D-21-00582 


\section{Supplementary data}

Abbreviations

3D: three-dimensional

3DE: 3D echocardiography

AP: anteroposterior

ASD: atrial septal defect

CAU: caudal

CRA: cranial

CS: coronary sinus

CT: computed tomography

CW: continuous wave

FO: fossa ovalis

IAS: interatrial septum

ICE: intracardiac echocardiography

IVC: inferior vena cava

LA: left atrium

LAA: left atrial appendage

LAO: left anterior oblique

LAX: long axis

LV: left ventricular

LVOT: left ventricular outflow

MPR: multiplanar reconstruction

MR: mitral regurgitation

MV: mitral valve

PISA: proximal isovelocity surface area

PVL: paravalvular leak

PW: pulsed wave

RAO: right anterior oblique

RCA: right coronary artery

$\mathbf{R V}$ : right ventricular

SAX: short axis

SHD: structural heart diseases

SVC: superior vena cava

TCD: transcranial Doppler

TMVI: transcatheter mitral valve interventions

TOE: transoesophageal echocardiography

TR: tricuspid regurgitation

TSP: transseptal puncture

TTE: transthoracic echocardiography

TV: tricuspid valve

VSD: ventricular septal defects

VTI: velocity time integral

Supplementary Table 1. Transseptal puncture.

\begin{tabular}{|c|c|c|c|c|}
\hline \multirow{2}{*}{$\begin{array}{l}\text { Procedural } \\
\text { steps }\end{array}$} & \multicolumn{3}{|c|}{ Imaging modality } & \multirow[t]{2}{*}{ Considerations } \\
\hline & Echo & & Fluoroscopy & \\
\hline $\begin{array}{l}\text { 1. Advancement } \\
\text { of the TSP } \\
\text { catheter } \\
\text { towards the FO }\end{array}$ & -2D bicaval view & - & $\begin{array}{l}\text {-AP projection } \\
\text {-LAO } \\
\text { projection }\end{array}$ & \multirow[t]{2}{*}{$\begin{array}{l}\text {-In-depth knowledge of } \\
\text { the anatomy of IAS and } \\
\text { surrounding structures. } \\
\text {-Prompt identification } \\
\text { and recognition of }\end{array}$} \\
\hline 2. Correct & -2D bicaval view & -3D en-face view & •RAO & \\
\hline
\end{tabular}




\begin{tabular}{|c|c|c|c|c|}
\hline $\begin{array}{l}\text { position and } \\
\text { orientation of } \\
\text { the tip of the } \\
\text { catheter }\end{array}$ & $\begin{array}{l}\left(90-120^{\circ}\right) \text { for } \\
\text { superior-inferior } \\
\text { orientation } \\
\cdot \text { SAX view at the } \\
\text { base }\left(30-50^{\circ}\right) \text { for } \\
\text { anterior-posterior } \\
\text { orientation } \\
\text {-4-chamber view } \\
\left(0^{\circ}\right) \text { to determine } \\
\text { the height above } \\
\text { the MV } \\
\text {-Biplane view that } \\
\text { displays both the } \\
\text { bicaval and the } \\
\text { SAX views } \\
\text { simultaneously }\end{array}$ & $\begin{array}{l}\text { of IAS from the } \\
\text { RA } \\
\text {-3D oblique } \\
\text { perspective of } \\
\text { IAS from the RA } \\
\text {-3D lateral } \\
\text { perspective of } \\
\text { IAS } \\
\text { (corresponding } \\
\text { to bicaval view) }\end{array}$ & $\begin{array}{l}\text { projection: the } \\
\text { IAS is } \\
\text { displayed in en } \\
\text { face } \\
\text { perspective } \\
\text {-AP } \\
\text { projection: the } \\
\text { IAS is } \\
\text { displayed in } \\
\text { an oblique } \\
\text { perspective } \\
\text {-LAO } \\
\text { projection } \\
\text { showing side- } \\
\text { on profile of } \\
\text { the IAS }\end{array}$ & \multirow{4}{*}{$\begin{array}{l}\text { anatomical landmarks } \\
\text { (i.e., aorta, SVC, IVC) in } \\
\text { the echocardiographic } \\
\text { views } \\
\text {-Use a standardised } \\
\text { protocol to minimise } \\
\text { serious complications } \\
\text {-Consider anatomical } \\
\text { variations or complex } \\
\text { anatomies that can } \\
\text { change the spatial } \\
\text { relationship between the } \\
\text { FO and the surrounding } \\
\text { structures } \\
\text {-Orientation by } \\
\text { fluoroscopic and } \\
\text { echocardiographic } \\
\text { views: sometimes the } \\
\text { fluoroscopic view does } \\
\text { not match with the } \\
\text { standard anatomical } \\
\text { view } \\
\text { •Associate the tactile } \\
\text { feedback with the } \\
\text { visualisation of the } \\
\text { movement of the } \\
\text { catheter through the } \\
\text { structures } \\
\text { •Adapt the procedure to } \\
\text { specific subsequent } \\
\text { structural interventions }\end{array}$} \\
\hline $\begin{array}{l}\text { 3. The catheter } \\
\text { is against the } \\
\text { FO "tenting" }\end{array}$ & $\begin{array}{l}\text {-2D bicaval view } \\
\text {-SAX view } \\
\text {-4-chamber view } \\
\left(0^{\circ}\right) \text { to determine } \\
\text { the height above } \\
\text { the MV } \\
\text {-Biplane view }\end{array}$ & $\begin{array}{l}\text {-3D lateral } \\
\text { perspective of } \\
\text { IAS }\end{array}$ & 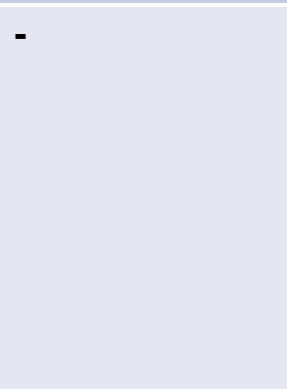 & \\
\hline $\begin{array}{l}\text { 4. Septal } \\
\text { crossing }\end{array}$ & $\begin{array}{l}\text {-Off-axis view } \\
\text { obtained } \\
\text { angling the beam } \\
\text { between SAX and } \\
\text { bicaval views }\end{array}$ & $\begin{array}{l}\text {-3D overhead of } \\
\text { LA }\end{array}$ & -AP projection & \\
\hline $\begin{array}{l}\text { 5. Passage of } \\
\text { the dilator and } \\
\text { sheath across } \\
\text { the septum }\end{array}$ & $\begin{array}{l}\text {-Off-axis view } \\
\text { obtained } \\
\text { angling the beam } \\
\text { between SAX and } \\
\text { bicaval views }\end{array}$ & $\begin{array}{l}\text {-3D overhead of } \\
\text { LA }\end{array}$ & -AP projection & \\
\hline
\end{tabular}


Supplementary Table 2. LAA closure procedure.

\begin{tabular}{|c|c|c|c|c|}
\hline \multirow{2}{*}{$\begin{array}{l}\text { Procedural } \\
\text { steps }\end{array}$} & \multicolumn{3}{|c|}{ Imaging modality } & \multirow[t]{2}{*}{ Considerations } \\
\hline & Echo & & Fluoroscopy & \\
\hline 1. TSP & See TSP $p$ & cedure & $\begin{array}{l}\text { See TSP } \\
\text { procedure }\end{array}$ & See TSP procedure \\
\hline $\begin{array}{l}\text { 2. Wires and } \\
\text { catheters } \\
\text { navigation in } \\
\text { LA }\end{array}$ & $\begin{array}{l}\text {-2D TOE } \\
\text { 4- } \\
\text { chamber } \\
\text { view }\end{array}$ & $\begin{array}{l}\cdot 3 \mathrm{D} \\
\text { over } \\
\text { head of } \\
\text { LA }\end{array}$ & -AP projection & - \\
\hline 3. LAA sizing & $\begin{array}{l}-2 D \text { TOE } \\
0^{\circ}-60^{\circ} \\
90^{\circ}-135^{\circ}\end{array}$ & $\begin{array}{l}-3 D \\
\text { MPR }\end{array}$ & $\begin{array}{l}\cdot \mathbf{R A O} \text { CRA } \\
\cdot \mathbf{R A O ~ C A U}\end{array}$ & $\begin{array}{l}\text {-RAO CRA } 20^{\circ} \text { view is equivalent to } \\
\text { approximately } 45^{\circ} \text { on TOE and shows } \\
\text { the minor axis of the LAA ostium } \\
\text {-RAO CAU } 20^{\circ} \text { projection is } \\
\text { equivalent to approximately } 135^{\circ} \text { view } \\
\text { on TOE and shows the major axis of } \\
\text { the LAA ostium }\end{array}$ \\
\hline $\begin{array}{l}\text { 4. LAA } \\
\text { cannulation }\end{array}$ & $\begin{array}{l}\cdot 2 \mathrm{D} \\
\text { biplane } \\
\text { views }\end{array}$ & $\begin{array}{l}-3 D \text { en } \\
\text { face of } \\
\text { LAA }\end{array}$ & $\begin{array}{l}\cdot \mathbf{R A O} \text { CRA } \\
\cdot \mathbf{R A O ~ C A U}\end{array}$ & $\begin{array}{l}\text {-Same fluoroscopic projection can be } \\
\text { maintained throughout the procedure }\end{array}$ \\
\hline $\begin{array}{l}\text { 5. Device } \\
\text { deployment }\end{array}$ & $\begin{array}{l}\cdot 2 \mathrm{D} \\
\text { biplane } \\
\text { views }\end{array}$ & $\begin{array}{l}\cdot 3 \mathrm{D} \\
\text { real } \\
\text { time } \\
\text { MPR }\end{array}$ & $\begin{array}{l}\cdot \mathbf{R A O} \text { CRA } \\
\cdot \text { RAO CAU }\end{array}$ & $\begin{array}{l}\text {-After LAA cannulation both the TOE } \\
\text { and the C-arm can be dedicated to } \\
\text { image only the LAA }\end{array}$ \\
\hline $\begin{array}{l}\text { 5. Evaluation } \\
\text { of device } \\
\text { positioning } \\
\text { including tug } \\
\text { test }\end{array}$ & $\begin{array}{l}\cdot 2 \mathrm{D} \text { TOE } \\
0^{\circ}-60^{\circ} \\
90^{\circ}-135 \\
\cdot 2 \mathrm{D} \\
\text { biplane } \\
\text { views }\end{array}$ & $\begin{array}{l}\cdot 3 D \\
\text { real } \\
\text { time } \\
\text { MPR }\end{array}$ & $\begin{array}{l}\text {-RAO CRA } \\
\text { without and } \\
\text { with } \\
\text { angiography } \\
\text {-RAO CAU } \\
\text { without and } \\
\text { with } \\
\text { angiography }\end{array}$ & $\begin{array}{l}\text {-Based on the complexity of the LAA } \\
\text { one or more fluoroscopic projections } \\
\text { will be needed during the implantation } \\
\text { and assessment of the results while } \\
\text { multiple TOE views or biplane view } \\
\text { are normally required to image the } \\
\text { occluder inside the LAA }\end{array}$ \\
\hline $\begin{array}{l}\text { 6. Device } \\
\text { release }\end{array}$ & $\begin{array}{l}\cdot 2 \mathrm{D} \\
\text { biplane } \\
\text { views }\end{array}$ & $\begin{array}{l}\cdot 3 D \\
\text { real } \\
\text { time } \\
\text { MPR }\end{array}$ & - RAO CRA & - \\
\hline $\begin{array}{l}\text { 7. Post- } \\
\text { delivery } \\
\text { evaluation }\end{array}$ & $\begin{array}{l}\cdot 2 \mathrm{D} \text { TOE } \\
0^{\circ}-60^{\circ} \\
90^{\circ}-135\end{array}$ & $\begin{array}{l}\cdot 2 \mathrm{D} \\
\text { TOE } \\
0^{\circ}-60^{\circ}, \\
90^{\circ}- \\
135 \\
\cdot 3 \mathrm{D} \text { en } \\
\text { face of } \\
\text { LAA }\end{array}$ & $\begin{array}{l}\text {-RAO CRA } \\
\text { without and } \\
\text { with } \\
\text { angiography } \\
\text {-RAO CAU } \\
\text { without and } \\
\text { with } \\
\text { angiography }\end{array}$ & - \\
\hline
\end{tabular}


Supplementary Table 3. Suitability for transcatheter leaflet approach repair.

\section{UNSUITABLE ANATOMY}

\begin{tabular}{|c|c|}
\hline MR jet & $\begin{array}{ll}- & \text { Multiple jets } \\
\text { - } & \text { Extreme commissural jets } \\
\text { - } & \text { Large }(>50 \%) \text { intercommissural extension of the regurgitant jet }\end{array}$ \\
\hline $\begin{array}{l}\text { Leaflets } \\
\text { morphology }\end{array}$ & $\begin{array}{ll}\text { - } & \text { Significant calcification in the grasping area } \\
\text { - } & \text { Perforation } \\
\text { - } & \text { Significant cleft } \\
\text { - } & \text { Severe restricted leaflet motion } \\
\text { - } & \text { Leaflet length }<8 \mathrm{~mm} \\
\text { - } & \text { Barlow's disease with multiple prolapsing scallops } \\
\text { - } & \text { Flail width }>15 \mathrm{~mm} \\
\text { - } & \text { Flail gap }>10 \mathrm{~mm}\end{array}$ \\
\hline Other & $\begin{array}{ll}\text { - } & \text { MV area }<3 \mathrm{~cm}^{2} / \text { haemodynamic significant mitral stenosis (mean G } \\
& >5 \mathrm{mmHg} \text { ) } \\
\text { - } & \text { Severe annular/subvalvular/leaflet calcification } \\
\text { - } & \text { TSP height }<3.5 \mathrm{~cm} \\
\text { - } & \text { Very small PFO } \\
\text { - } & \text { Very poor TOE imaging quality }\end{array}$ \\
\hline
\end{tabular}


Supplementary Table 4. Leaflets approach procedure.

\begin{tabular}{c|c|c|c|}
$\begin{array}{c}\text { Procedural } \\
\text { steps }\end{array}$ & \multicolumn{2}{|c|}{ Imaging modality } & Considerations \\
& Echo & Fluoroscopy & \\
\hline
\end{tabular}

MitraClip/PASCAL

MitraClip/PASCAL

\begin{tabular}{|c|c|c|c|}
\hline 1. TSP & \multicolumn{2}{|l|}{ See TSP } & See TSP \\
\hline $\begin{array}{l}\text { 2. GC/DS } \\
\text { advancement } \\
\text { into LA }\end{array}$ & $\begin{array}{l}\text {-Off-axis view } \\
\text { obtained } \\
\text { angling the } \\
\text { beam between } \\
\text { SAX and } \\
\text { bicaval views } \\
\text {-4-chamber } \\
\text { view }\end{array}$ & $\begin{array}{l}\cdot 3 \mathrm{D} \\
\text { overhead } \\
\text { of LA }\end{array}$ & AP projection \\
\hline
\end{tabular}

-Optimal TSP height is $\geq \mathbf{4 5}$ mm

-Desired TSP location is mid-fossa and posterior -According to aetiology: prolapse/flail: $\sim 4.5-5 \mathrm{~cm}$ above the mitral annulus; secondary MR with apical tethering: $\sim 3.5-4.0 \mathrm{~cm}$ above the annular plane.

-PASCAL: use 3D view of septum to ensure guide sheath tip flexes parallel to MV

-3D overhead perspective of the LA offers a comprehensive view of spatial relationships -2D imaging that thanks to the better spatial resolution allows to evaluate the relationship between the device and LA structures.

\begin{tabular}{|c|c|c|c|c|}
\hline $\begin{array}{l}\text { 3. Steering } \\
\text { and } \\
\text { positioning }\end{array}$ & $\begin{array}{l}\text {-Biplane views } \\
\text { (commissural } \\
\text { and LAX } \\
\text { views) }\end{array}$ & $\begin{array}{l}\cdot 3 D \\
\text { overhead } \\
\text { of LA }\end{array}$ & RAO CRA & \\
\hline $\begin{array}{l}\text { 4. Axial } \\
\text { alignment }\end{array}$ & $\begin{array}{l}\text {-Biplane views } \\
\text { (commissural } \\
\text { and LAX } \\
\text { views) }\end{array}$ & & RAO CRA & \\
\hline $\begin{array}{l}\text { 5. Device } \\
\text { orientation }\end{array}$ & $\begin{array}{l}\text {-Biplane views } \\
\text { (commissural } \\
\text { and LAX } \\
\text { views) } \\
\text { •SAX } \\
\text { transgastric } \\
\text { view }\end{array}$ & $\begin{array}{l}\cdot 3 \mathrm{D} \text { en } \\
\text { face view } \\
\text { of } \mathrm{MV}\end{array}$ & RAO CRA & $\begin{array}{l}\text {-PASCAL: identify } \\
\text { anterior and posterior } \\
\text { clasp } \\
\text {-No arms/ paddles should } \\
\text { be seen in the commissural } \\
\text { view and RAO CRA } \\
\text { projection, while should be } \\
\text { visualised in full length in } \\
\text { LAX view. In cases of } \\
\text { commissural targets, it }\end{array}$ \\
\hline
\end{tabular}




\begin{tabular}{|c|c|c|c|c|}
\hline & & & & $\begin{array}{l}\text { could be useful to look for } \\
\text { arms/paddles fully opened } \\
\text { in LAX. }\end{array}$ \\
\hline $\begin{array}{l}6 . \text { System } \\
\text { advancement } \\
\text { into LV }\end{array}$ & $\begin{array}{l}\text {-Biplane views } \\
\text { (commissural } \\
\text { and LAX } \\
\text { views) }\end{array}$ & & RAO CRA & $\begin{array}{l}\text {-The correct positioning } \\
\text { and orientation are } \\
\text { rechecked under } \\
\text { simultaneous biplane views } \\
\text { and 3D en face view. }\end{array}$ \\
\hline $\begin{array}{l}\text { 7. Leaflets } \\
\text { capture }\end{array}$ & $\begin{array}{l}\text {-Biplane views } \\
\text { (commissural } \\
\text { and LAX } \\
\text { views) }\end{array}$ & & RAO CRA & $\begin{array}{l}\text {-PASCAL: check for } \\
\text { clasp(s) bouncing. }\end{array}$ \\
\hline $\begin{array}{l}\text { 8. Evaluation } \\
\text { of leaflets } \\
\text { insertion }\end{array}$ & $\begin{array}{l}\text {-2D LAX, 4- } \\
\text { chamber and } \\
\text { commissural } \\
\text { view } \\
\text {-Biplane views } \\
\text { •SAX } \\
\text { transgastric } \\
\text { view }\end{array}$ & $\begin{array}{l}\text { •3D en } \\
\text { face view } \\
\text { of MV } \\
\text { •3D MPR }\end{array}$ & - & $\begin{array}{l}\text {-Review recordings of } \\
\text { clasp(s)/gripper(s) lowering } \\
\text { and device closure } \\
\text {-Evaluate direct and } \\
\text { indirect signs: adequate } \\
\text { length of the leaflet inside } \\
\text { the arms/paddles (at least } \\
\geq 5 \mathrm{~mm}) \text {; reduced mobility; } \\
\text { the occurrence of a double } \\
\text { MV orifice at 3D en face } \\
\text { view of MV, MR reduction, } \\
\text { the absence of intraclip jet, } \\
\text { LASEC. }\end{array}$ \\
\hline $\begin{array}{l}\text { 9. Results } \\
\text { evaluation }\end{array}$ & \multicolumn{4}{|c|}{ See Supplementary Table 5} \\
\hline $\begin{array}{l}\text { 10. Device } \\
\text { release }\end{array}$ & •Biplane views & & RAO CRA & \\
\hline $\begin{array}{l}\text { 11. System } \\
\text { removal }\end{array}$ & $\begin{array}{l}\text {-Multiple 2D } \\
\text { ME views }\end{array}$ & & RAO CRA & \\
\hline $\begin{array}{l}\text { 12. ASD } \\
\text { evaluation }\end{array}$ & $\begin{array}{l}\text {-2D bicaval } \\
\text { view with and } \\
\text { without colour } \\
\text { Doppler } \\
\text {-Biplane view } \\
\text { with and } \\
\text { without colour } \\
\text { Doppler }\end{array}$ & $\begin{array}{l}\cdot 3 D \text { en } \\
\text { face view } \\
\text { of the } \\
\text { IAS }\end{array}$ & - & \\
\hline
\end{tabular}

DS: delivery system; GC: guide catheter; ME: midoesophageal 
Supplementary Table 5. Echocardiographic and haemodynamic parameters for grading MR severity leaflets repair.

\begin{tabular}{|c|c|}
\hline Parameters & Considerations \\
\hline HAEMODYNAMIC PARAMETERS \\
\hline
\end{tabular}

\section{Left atrial pressure Reduction of a regurgitant $\mathrm{V}$ (LAP) wave/reduction of LAP}

-Load dependent

-Affected by other haemodynamic factors (i.e., anaesthetic drugs)

-Load dependent -Affected by other haemodynamic factors (i.e., anaesthetic drugs)

\section{ECHOCARDIOGRAPHIC PARAMETERS}

\section{Mild MR}

Few small, narrow jets

\begin{tabular}{|l|l|l|}
\hline Qualitative & MR reduction & Mild MR
\end{tabular}

\section{Colour-Doppler jet}

- size

- eccentricity

Flow convergence size (at a Nyquist limit 25$40 \mathrm{~cm} / \mathrm{s}$ )

Mitral inflow pattern

Decrease E-wave velocity/decrease inflow VTI

Reduction of flow convergence

Increase in forward systolic component pattern

CW Doppler of MR jet (density, contour)

PW LVOT

(stroke volume, $\mathrm{SV}$ )

Left atrial spontaneous echocontrast (LASEC)

\section{Increase in VTI LVOT}

Appearance/increase
- number
Decrease in density and modification of the shape

\section{None or} small

\section{A-wave dominant}

Systolic dominant
-Multiple jets can lead to overestimation

-Device artefacts/shadowing may mask jets -Eccentric jets difficult to evaluate

-Affected by technical and haemodynamic factors

-Device artefacts/shadowing may mask jets -Influenced by technical and haemodynamic factors

-Affected by multiple factors: relative MV obstruction, $L V$ filling pressure, atrial fibrillation

-Influenced by many factors:

LV diastolic function, atrial fibrillation, LA pressure.

Faint, $\quad$ Angle dependency parabolic Difficult for eccentric jets contour
-Affected by multiple haemodynamic factors

-Not specific/not frequent 


\begin{tabular}{|c|c|c|c|}
\hline Semi-quantitative & & & \\
\hline $\begin{array}{l}\text { Vena contracta (VC) } \\
\text { width }\end{array}$ & $\begin{array}{l}\text { Not specific/not } \\
\text { frequent }\end{array}$ & $\leq 0.3 \mathrm{~cm}$ & $\begin{array}{l}\text {-Not validated for multiple } \\
\text { jets } \\
\text { •Difficult for eccentric jets }\end{array}$ \\
\hline \multicolumn{4}{|l|}{ Quantitative } \\
\hline $\begin{array}{l}\text { 3D vena contracta } \\
\text { Area }\end{array}$ & VCA reduction & $<0.2 \mathrm{~cm}^{2}$ & $\begin{array}{l}\text {-Likely a preferred method } \\
\text { but limited studies available } \\
\text {-Technical } \\
\text { dependence/artefacts }\end{array}$ \\
\hline $\begin{array}{l}\text { Regurgitant volume } \\
\text { (RV) }\end{array}$ & $\mathrm{RV}$ reduction & & $\begin{array}{l}\text { - Requires excellent } L V \\
\text { endocardial definition=> best } \\
\text { with } 3 D \text { echo or contrast } \\
\text { echo } \\
\text {-Cannot use mitral annulus } \\
\text { site for flow because of MV } \\
\text { devices (except MV } \\
\text { annuloplasty) } \\
\text {-Multiple measurements may } \\
\text { compound errors }=> \\
\text { technically difficult } \\
\text {-Not accurate if }>\text { mild aortic } \\
\text { regurgitation or VSD present }\end{array}$ \\
\hline $\begin{array}{l}\text { Regurgitant fraction } \\
\text { (RF) }\end{array}$ & RF reduction & $<30 \%$ & \\
\hline
\end{tabular}


Supplementary Table 6. Cardioband procedure.

\begin{tabular}{|l|l|l|l|}
\hline Procedural steps & \multicolumn{2}{|c|}{ Imaging modality } & \multicolumn{1}{c|}{ Considerations } \\
\hline 1. TSP & Echo & Fluoroscopy & \\
\hline See TSP & See TSP & $\begin{array}{l}\text { Optimal TSP height from } \\
\text { annular plane: }>3.5 \text { cm } \\
\text { from MV. The puncture } \\
\text { site must be straight above } \\
\text { the posteromedial } \\
\text { commissure (3D overhead } \\
\text { perspective of LA or en- } \\
\text { face view of IAS from the } \\
\text { antero-lateral commissural } \\
\text { perspective. }\end{array}$ \\
\hline
\end{tabular}

\begin{tabular}{|l|l|l|l|}
\hline 2. TSS insertion & $\begin{array}{l}\text {-2D SAX at } \\
\text { the base }\end{array}$ & $\begin{array}{l}\text {-3D } \\
\text { overhead } \\
\text { perspective } \\
\text { of LA }\end{array}$ & $\begin{array}{l}\text {-AP } \\
\text { projection }\end{array}$ \\
\hline $\begin{array}{l}\text { 3. Navigation inside } \\
\text { LA }\end{array}$ & $\begin{array}{l}\text {-Several 3D } \\
\text { perspectives }\end{array}$ & -LAO CAU \\
\hline
\end{tabular}

\begin{tabular}{|l|l|l|l|}
\hline $\begin{array}{l}\text { 4. Implant } \\
\text { deployment }\end{array}$ & $\begin{array}{l}\text {-2D biplane } \\
\text { views }\end{array}$ & - -3D MPR & $\begin{array}{l}\text {-2D and biplane views or } \\
\text { MPR are used to assess the } \\
\text { proper distance from the } \\
\text { hinge point of posterior }\end{array}$ \\
\hline & & $\begin{array}{l}\text { leaflet and the device } \\
\text { angulation. }\end{array}$ \\
\hline & & $\begin{array}{l}\text {-The anchoring is checked } \\
\text { via a push-and-pull test. }\end{array}$ \\
\hline
\end{tabular}

5. ISD removal and SAT insertion

\section{Implant size adjustment/cinching}

7. Results evaluation

\begin{tabular}{|c|c|}
\hline $\begin{array}{l}\text {-2D biplane } \\
\text { views }\end{array}$ & $\begin{array}{l}\text {-3D } \\
\text { overhead of } \\
\text { LA }\end{array}$ \\
\hline
\end{tabular}

-2D colour

Doppler

-2D biplane

views

-Transmitral gradient
-3D

overhead of

LA

-3D en face

view of MV
-LAO CAU

-LAO CAU 
Supplementary Table 7. Echocardiographic Imaging of tricuspid valve.

\begin{tabular}{|c|c|c|c|}
\hline \multicolumn{2}{|r|}{ TOE } & \multicolumn{2}{|r|}{$3 D$} \\
\hline View & Considerations & View & Considerations \\
\hline •ME 4-chamber view & & $\begin{array}{l}\cdot \text { En } \\
\text { face } \\
\text { view of } \\
\text { TV }\end{array}$ & $\begin{array}{l}\text {-3D data set must include } \\
\text { aortic valve and IAS as } \\
\text { anatomical landmarks for } \\
\text { orientation }\end{array}$ \\
\hline $\begin{array}{l}\bullet M E \text { RV } \\
\text { inflow/outflow view }\end{array}$ & $\begin{array}{l}\text {-Equivalent to commissural } \\
\text { view for the MV }\end{array}$ & & \\
\hline $\begin{array}{l}\text {-Biplane views } \\
\text { starting from RV } \\
\text { inflow/outflow views }\end{array}$ & $\begin{array}{l}\text {-Essential procedural } \\
\text { reference view for anterior- } \\
\text { posterior and septal-lateral } \\
\text { orientation }\end{array}$ & & \\
\hline •ME bicaval view & & & \\
\hline $\begin{array}{l}\text {-Transgastric short } \\
\text { axis and RV inflow } \\
\text { views }\end{array}$ & $\begin{array}{l}\text {-Essential procedural } \\
\text { reference views for } \\
\text { orientation and positioning of } \\
\text { the devices }\end{array}$ & & \\
\hline
\end{tabular}


Supplementary Table 8. Procedural steps of direct annuloplasty of TV.

\begin{tabular}{|c|c|c|c|c|}
\hline \multirow[t]{2}{*}{ Procedural steps } & \multicolumn{3}{|c|}{ Imaging modality } & Considerations \\
\hline & \multicolumn{2}{|l|}{ Echo } & Fluoroscopy & \\
\hline 1. System insertion & $\begin{array}{l}\cdot 2 \mathrm{D} \\
\text { bicaval } \\
\text { view } \\
\text {-Biplane } \\
\text { view }\end{array}$ & & $\begin{array}{l}- \text { AP } \\
\text { projection }\end{array}$ & \\
\hline $\begin{array}{l}\text { 2. Navigation inside } \\
\text { RA }\end{array}$ & & $\begin{array}{l}\text {-3D overhead } \\
\text { perspective } \\
\text { of RA }\end{array}$ & •LAO CAU & \\
\hline $\begin{array}{l}\text { 2. Implant } \\
\text { deployment }\end{array}$ & $\begin{array}{l}\cdot 2 \mathrm{D} \\
\text { biplane } \\
\text { views }\end{array}$ & •3D MPR & $\begin{array}{l}\text {-RAO } \\
\text { projections } \\
\text {-RCA } \\
\text { angiography }\end{array}$ & $\begin{array}{l}\text {-2D and biplane views or } \\
\text { MPR are used to assess the } \\
\text { proper distance from the } \\
\text { hinge point of posterior } \\
\text { leaflet and the device } \\
\text { angulation. } \\
\text {-The anchoring is checked } \\
\text { via a push-and-pull test. }\end{array}$ \\
\hline 3. Pull test & $\begin{array}{l}\cdot 2 \mathrm{D} \\
\text { biplane } \\
\text { views }\end{array}$ & & $\begin{array}{l}\cdot \mathrm{RAO} \\
\text { projections }\end{array}$ & \\
\hline $\begin{array}{l}\text { 4. Implant size } \\
\text { adjustment/cinching }\end{array}$ & & $\begin{array}{l}\text {-3D overhead } \\
\text { perspective } \\
\text { of RA }\end{array}$ & •LAO CAU & \\
\hline 5. Results evaluation & $\begin{array}{l}-2 D \text { colour } \\
\text { Doppler } \\
\text {-2D } \\
\text { biplane } \\
\text { views } \\
\text {-Trans- } \\
\text { tricuspid } \\
\text { gradient }\end{array}$ & $\begin{array}{l}-3 D \text { en face } \\
\text { perspective } \\
\text { of } \mathrm{TV}\end{array}$ & & \\
\hline
\end{tabular}


Supplementary Table 9. Tricuspid leaflets approach.

\begin{tabular}{|c|c|c|c|c|}
\hline \multirow{2}{*}{$\begin{array}{l}\text { Procedural } \\
\text { steps }\end{array}$} & \multicolumn{3}{|c|}{ Imaging modality } & \multirow[t]{2}{*}{ Considerations } \\
\hline & \multicolumn{2}{|l|}{ Echo } & Fluoroscopy & \\
\hline & \multicolumn{2}{|c|}{ MitraClip/PASCAL } & MitraClip/PASCAL & \\
\hline $\begin{array}{l}\text { 1. GS/DS } \\
\text { advancement } \\
\text { into RA }\end{array}$ & $\begin{array}{l}\text {-Bicaval view } \\
\text {-2D biplane } \\
\text { view }\end{array}$ & $\begin{array}{l}\text {-3D } \\
\text { overhead } \\
\text { perspective } \\
\text { of RA }\end{array}$ & -AP projection & \\
\hline $\begin{array}{l}\text { 2. Steering } \\
\text { and } \\
\text { positioning }\end{array}$ & $\begin{array}{l}\text { •ME biplane } \\
\text { view starting } \\
\text { from RV inflow- } \\
\text { outflow view } \\
\text {-Transgastric } \\
\text { RV inflow } \\
\text { including IVC }\end{array}$ & $\begin{array}{l}\text {-3D en face } \\
\text { view of } T V\end{array}$ & -RAO projections & \\
\hline $\begin{array}{l}\text { 3. Axial } \\
\text { alignment and } \\
\text { trajectory }\end{array}$ & $\begin{array}{l}\text { •ME biplane } \\
\text { view starting } \\
\text { from RV inflow- } \\
\text { outflow view } \\
\text {-Biplane } \\
\text { transgastric } \\
\text { SAX and RV }\end{array}$ & & -RAO projections & \\
\hline $\begin{array}{l}\text { 4. Device } \\
\text { orientation }\end{array}$ & $\begin{array}{l}\text {-Transgastric } \\
\text { SAX view }\end{array}$ & & -RAO projections & $\begin{array}{l}\text {-PASCAL: identify } \\
\text { each clasp } \\
\text {-Paddles/clip arms } \\
\text { perpendicular to the } \\
\text { coaptation line }\end{array}$ \\
\hline $\begin{array}{l}\text { 5. System } \\
\text { advancement } \\
\text { into } R V\end{array}$ & $\begin{array}{l}- \text { Biplane } \\
\text { transgastric } \\
\text { SAX and RV }\end{array}$ & & -RAO projections & \\
\hline $\begin{array}{l}\text { 6. Leaflets } \\
\text { capture }\end{array}$ & $\begin{array}{l}\text { •ME biplane } \\
\text { views (ME } \\
\text { inflow-outflow) } \\
\text {-Transgastric } \\
\text { SAX view }\end{array}$ & & -RAO projections & $\begin{array}{l}\text {-PASCAL: check for } \\
\text { clasp(s) bouncing } \\
\text { •Adjust viewer angle in } \\
\text { ME inflow-outflow } \\
\text { view plane to find } \\
\text { narrow profile of the } \\
\text { implant and full } \\
\text { opened clasps arms in } \\
\text { the derived view }\end{array}$ \\
\hline $\begin{array}{l}\text { 7. Evaluation } \\
\text { of leaflets } \\
\text { insertion }\end{array}$ & $\begin{array}{l}\text {-Transgastric } \\
\text { SAX view } \\
\text {-ME biplane } \\
\text { views }\end{array}$ & & & $\begin{array}{l}\text {-Limited leaflet } \\
\text { mobility } \\
\text {-TR reduction }\end{array}$ \\
\hline
\end{tabular}




\begin{tabular}{|l|l|l|l|}
\hline $\begin{array}{l}\text { 8. Results } \\
\text { evaluation }\end{array}$ & $\begin{array}{l}\text {-Colour } \\
\text { Doppler } \\
\text {-Inflow gradient }\end{array}$ & $\begin{array}{l}\text {-3D colour } \\
\text { Doppler }\end{array}$ & \\
\hline $\begin{array}{l}\text { 9. System } \\
\text { removal }\end{array}$ & -2D ME views & $\begin{array}{l}\text {-3D } \\
\text { overhead } \\
\text { perspective } \\
\text { of RA }\end{array}$ & •AP projection \\
\hline
\end{tabular}


Supplementary Table 10. PFO/ASD closure.

\begin{tabular}{|c|c|c|c|c|}
\hline \multirow[t]{2}{*}{ Procedural steps } & \multicolumn{3}{|c|}{ Imaging modality } & \multirow[t]{2}{*}{ Considerations } \\
\hline & Echo & & Fluoroscopy & \\
\hline \multirow[t]{4}{*}{$\begin{array}{l}\text { 1. Baseline } \\
\text { evaluation }\end{array}$} & & $\begin{array}{l}\cdot 3 D \text { en } \\
\text { face of } \\
\text { IAS } \\
\cdot 3 D \text { MPR }\end{array}$ & & \\
\hline & $\begin{array}{l}\text {-2D SAX at base }\left(0^{\circ} \text { - }\right. \\
\left.45^{\circ}\right)\end{array}$ & & & $\begin{array}{l}\text {-Aortic rim and } \\
\text { posterior-inferior rim }\end{array}$ \\
\hline & •Bicaval view & & & $\begin{array}{l}\text {-Superior and inferior } \\
\text { caval rim }\end{array}$ \\
\hline & •ME 4-chamber view & & & $\begin{array}{l}\text {-Anterior-inferior and } \\
\text { posterior-superior rim }\end{array}$ \\
\hline $\begin{array}{l}\text { 1. PFO/ASD } \\
\text { crossing }\end{array}$ & $\begin{array}{l}\text {-Bicaval view } \\
\text {-ME SAX at the base } \\
\text {-Biplane views (bicaval, } \\
\text { SAX view) }\end{array}$ & $\begin{array}{l}\cdot 3 D \text { en- } \\
\text { face view } \\
\text { of IAS }\end{array}$ & $\begin{array}{l}\bullet A P \\
\text { projection } \\
\cdot \text { LAO CRA }\end{array}$ & \\
\hline $\begin{array}{l}\text { 2. Delivery sheath } \\
\text { across the IAS }\end{array}$ & $\begin{array}{l}\text {-Bicaval view } \\
\text {-ME SAX at the base } \\
\text {-Biplane views (bicaval, } \\
\text { SAX view) }\end{array}$ & $\begin{array}{l}-3 D \text { en- } \\
\text { face view } \\
\text { of IAS }\end{array}$ & $\begin{array}{l}\bullet A P \\
\text { projection } \\
\cdot \text { LAO CRA }\end{array}$ & \\
\hline $\begin{array}{l}\text { 3. Sizing balloon, } \\
\text { in case of ASD } \\
\text { closure }\end{array}$ & $\begin{array}{l}\text {-Biplane views (bicaval, } \\
\text { SAX view) with and } \\
\text { without colour Doppler }\end{array}$ & & $\begin{array}{l}\bullet A P \\
\text { projection } \\
\text {-LAO CRA }\end{array}$ & \\
\hline $\begin{array}{l}\text { 4. Device } \\
\text { positioning }\end{array}$ & $\begin{array}{l}\cdot M E \text { view at } 45^{\circ}-60^{\circ} \\
90-105^{\circ}\end{array}$ & $\begin{array}{l}\cdot 3 D \text { en- } \\
\text { face view } \\
\text { of IAS }\end{array}$ & $\begin{array}{l}\text { •AP } \\
\text { projection } \\
\text {-LAO CRA }\end{array}$ & \\
\hline $\begin{array}{l}\text { 5. Stability } \\
\text { manoeuvre }\end{array}$ & •Bicaval view & & $\begin{array}{l}\bullet A P \\
\text { projection } \\
\text {-LAO CRA }\end{array}$ & \\
\hline 6. Release & -Bicaval view & & $\begin{array}{l}\text { •AP } \\
\text { projection } \\
\text {-LAO CRA }\end{array}$ & \\
\hline $\begin{array}{l}\text { 7. Final } \\
\text { evaluation }\end{array}$ & $\begin{array}{l}\text {-Biplane views (bicaval, } \\
\text { SAX view) with and } \\
\text { without colour Doppler }\end{array}$ & $\begin{array}{l}-3 D \text { en- } \\
\text { face view } \\
\text { of IAS }\end{array}$ & & \\
\hline
\end{tabular}


Supplementary Table 11. Procedural steps of mitral PVL closure.

\begin{tabular}{|c|c|c|c|}
\hline Procedural steps & \multicolumn{3}{|c|}{ Imaging modality } \\
\hline & Echo & & Fluoroscopy \\
\hline 1. TSP & See TSP & & See TSP \\
\hline $\begin{array}{l}\text { 2. TAP: transapical } \\
\text { puncture in case of } \\
\text { retrograde approach }\end{array}$ & See TMVR & & See TMVR \\
\hline 3. Leak cannulation & $\begin{array}{l}\text {-ME biplane } \\
\text { view }\end{array}$ & $\begin{array}{l}\text {-3D en face view of } \\
\text { MV from LA and LV } \\
\text { perspectives }\end{array}$ & $\begin{array}{l}\text {-Personalised } \\
\text { fluoroscopic projection }\end{array}$ \\
\hline 4. Devise positioning & $\begin{array}{l}\text {-ME biplane } \\
\text { view }\end{array}$ & $\begin{array}{l}\text {-3D en face view of } \\
\text { MV from LA and LV } \\
\text { perspectives }\end{array}$ & $\begin{array}{l}\text {-Personalised } \\
\text { fluoroscopic projection }\end{array}$ \\
\hline $\begin{array}{l}\text { 5. Evaluation of residual } \\
\text { regurgitation }\end{array}$ & $\begin{array}{l}\text {-ME views with } \\
\text { colour Doppler }\end{array}$ & -3D colour Doppler & \\
\hline $\begin{array}{l}\text { 6. Evaluation of } \\
\text { prosthesis function }\end{array}$ & $\begin{array}{l}\text {-ME views with } \\
\text { colour-Doppler } \\
\text {-Transmitral } \\
\text { gradient }\end{array}$ & $\begin{array}{l}-3 D \text { en face view with } \\
\text { and without colour- } \\
\text { Doppler }\end{array}$ & $\begin{array}{l}\text {-Cinefluoroscopy } \\
\text { (assessment of leaflets } \\
\text { motion) }\end{array}$ \\
\hline 7. Release & •ME views & •3D en face view & \\
\hline 8. Results evaluation & $\begin{array}{l}\text {-ME views with } \\
\text { colour Doppler } \\
\text {-Transmitral } \\
\text { gradient }\end{array}$ & $\begin{array}{l}\text {-3D en face view with } \\
\text { colour Doppler }\end{array}$ & $\begin{array}{l}\text {-Personalised } \\
\text { fluoroscopic projection }\end{array}$ \\
\hline
\end{tabular}

